\title{
硫氰酸酯类化合物的合成及其应用研究进展
}

\author{
徐庆 ${ }^{a} \quad$ 张连阳 $^{b} \quad$ 冯高峰 ${ }^{a}$ 金城安 ${ }^{*, a}$ \\ ( ${ }^{a}$ 绍兴文理学院化学化工学院 绍兴 312000) \\ ( $b$ 绍兴文理学院纺织服装学院 绍兴 312000)
}

\begin{abstract}
摘要 硫氰酸酯类化合物(RSCN)作为重要的合成中间体，在农药、医药、材料等领域有着广泛的应用价值. 近年来，硫 氧酸酯的合成及其应用研究发展迅速, 不断有新的硫氰酸酯合成方法和以其为原料的转化反应涌现. 综述了近几年来 发展的硫氰酸酯合成方法及其转化应用, 为硫氰酸酯类化合物的合成和应用研究提供帮助.

关键词 硫氰酸酯; 合成方法; 应用
\end{abstract}

\section{Progress on the Synthesis and Applications of Thiocyanates}

\author{
Xu, Qing ${ }^{a} \quad$ Zhang, Lianyang $^{b} \quad$ Feng, Gaofeng $^{a} \quad$ Jin, Chengan ${ }^{*, a}$ \\ $\left({ }^{a}\right.$ College of Chemistry and Chemical Engineering, Shaoxing University, Shaoxing 312000) \\ ( ${ }^{b}$ College of Textile and Garment, Shaoxing University, Shaoxing 312000)
}

\begin{abstract}
Thiocyanates (RSCN) are important synthetic intermediates, which have been widely used for the synthesis of pesticides, medicines and materials. In recent years, great advances in the synthesis and transformations of this class of compounds have been made, and many synthetic applications of those compounds have been emerged. In this review, the synthetic methods and transformations of thiocyanates are introduced systematically, which may provide assistance for the studies of thiocyanates in this area.
\end{abstract}

Keywords thiocyanates; synthetic methods; application

硫氰酸酯(RSCN) 是一类含有硫氰基官能团的重要 氮硫类化合物(图 1), 具有多种生物活性, 如抑制酶活 性、杀虫活性、抗微生物活性等, 在医药和农药等领域 有着重要的应用价值 ${ }^{\left[{ }^{[\sim 5]}\right.}$. 此外, 硫氰酸酯类化合物也 广泛应用于有机合成领域 ${ }^{[6-11]}$. 作为重要的有机合成中 间体，硫氰酸酯通过简单转化就可得到硫醇、硫醚、异 硫氰酸酯、含硫杂环等多种有机硫化物，同时它还可作 为氰化试剂很好地参与反应. 由于硫氰酸酯具有良好的 生物活性和广阔的应用前景, 引起了有机合成工作者们 的浓厚研究兴趣.

近几十年来, 合成化学家们对硫氰酸酯类化合物的 合成与应用展开了较为深入的研究与探索. 2016 年, Gulea 等 ${ }^{[12]}$ 对硫氧酸酯的合成及应用做了相关总结. 最 近, 各种各样的硫氰酸酯类化合物合成新方法、新策略 又不断涌现, 有力推动着硫氧酸酯类化合物的制备向高 效、绿色合成方向发展. 本文着重介绍了近三年来硫氰

化物的合成进展，并对其应用进行了分类讨论，以期为 读者了解硫氰酸酯的研究动态提供帮助.

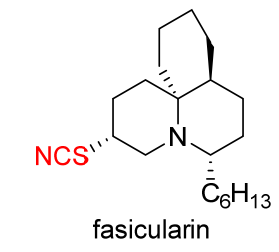<smiles>N#[Si]CCOc1ccc(Oc2ccccc2)cc1</smiles>

4-phenoxyphenoxyethyl thiocyanate

图 1 一些含有硫氰基团的活性分子

Figure 1 Selected bioactive molecules containing thiocyanate groups

\footnotetext{
* Corresponding author. E-mail: jca@usx.edu.cn Received July 8, 2018; revised August 27, 2018; published online September 17, 2018. Project supported by the Research Project of Shaoxing University (No. 2017LG1001). 绍兴文理学院校级科研(No. 2017LG1001)资助项目.
} 


\section{1 硫氰酸酯的合成}

合成硫氰酸酯主要有直接合成法和间接合成法两 种策略, 直接合成法通过底物与硫氰化试剂反应来合成 硫氰酸酯，主要包括 ${ }^{-} \mathrm{SCN}$ 亲核取代反应、 ${ }^{+} \mathrm{SCN}$ 亲电取 代反应、・SCN 自由基反应; 间接合成法利用有机硫化 物的氰化反应来得到硫氰酸酯, 主要包括 ${ }^{-} \mathrm{CN}$ 亲核取代 反应、 ${ }^{+} \mathrm{CN}$ 亲电取代反应、・ $\mathrm{CN}$ 自由基反应等.

\section{1 直接合成法}

\subsection{1亲核取代}

亲核取代反应是合成硫氰酸酯类化合物的经典方 法, 硫氰酸盐 $\left(\mathrm{NaSCN} 、 \mathrm{KSCN} 、 \mathrm{NH}_{4} \mathrm{SCN}\right)$ 和三甲基甲硅 烷基异硫氧酸酯(TMSNCS)是常见的亲核试剂，容易与 带有易离去基团的底物反应得到这类化合物.

$\mathrm{Hu}$ 小组 ${ }^{[13]}$ 于 2015 年利用 Chan-Lam 反应成功实现 了芳基硼酸与 TMSNCS 的交叉偶联反应. 在室温下，以 氯化亚铜为催化剂, 四甲基乙二胺(TMEDA)为配体, 氧 气作氧化剂, TMSNCS 可以与芳基嗍酸发生氧化偶联反 应，以 $45 \% \sim 98 \%$ 的收率得到各种芳基硫氰酸酯类化合 物. 通过控制实验, 推测可能的反应机理如下: (1)催化 剂 A 与产生的 ${ }^{-} \mathrm{SCN}$ 阴离子进行配体交换后形成具有反 应活性的物种 $\mathbf{B}$; (2) B 可被氧气氧化得到中间体 $\mathbf{C}$; (3) $\mathrm{C}$ 通过 $\mathrm{O}-\mathrm{B}$ 配位键的相互作用与两个芳基硼酸分子结 合; (4)芳基转移到铜原子上得到 $\mathbf{D}$, 随后分解成两个单 体铜(III)配合物 $\mathbf{E}$; (5) $\mathbf{E}$ 经历还原消除得到目标产物和 一价铜 $\mathbf{F} ;(6) \mathbf{F}$ 与 ${ }^{-} \mathrm{SCN}$ 阴离子交换以得到 $\mathbf{B}$ 并完成催 化循环(Scheme 1).

2015 年, Liu 课题组 ${ }^{[14]}$ 以 TMSNCS 为硫氰基源, Togni 试剂为三氟甲基源, 在铜催化下实现了联烯的硫 氰化三氟甲基化反应(Eq. 1). 该反应条件较为温和, 大 部分底物能以良好及以上的收率一步合成含两个重要 官能团的产物, 为三氟甲基化硫氰酸酯类化合物的合成 提供了新思路.

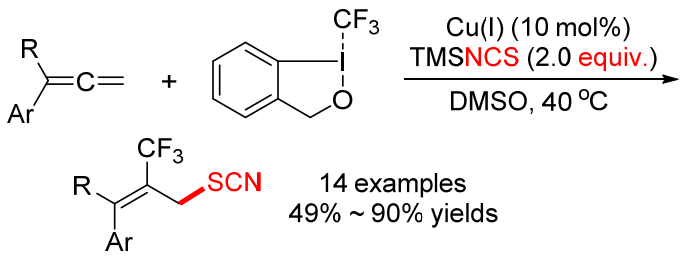

2017 年 $\mathrm{Wu}$ 课题组 ${ }^{[15]}$ 提出了一条硫氰化钾与(杂)芳 烃的硫氧化新路线(Scheme 2). 在 DMSO 溶剂中, 以 $\mathrm{Cu}(\mathrm{OTf})_{2}$ 作催化剂, TMEDA 为配体, 三氟化硼为添加 剂, 在氧气氛围中加热搅拌反应, 能以 $62 \%$ 95\%收率 分离得到各种硫氰化产物. 该体系底物普适性好, 对于 C-4 位不含取代基的苯胺可以得到 C-4 位硫氰化产物.
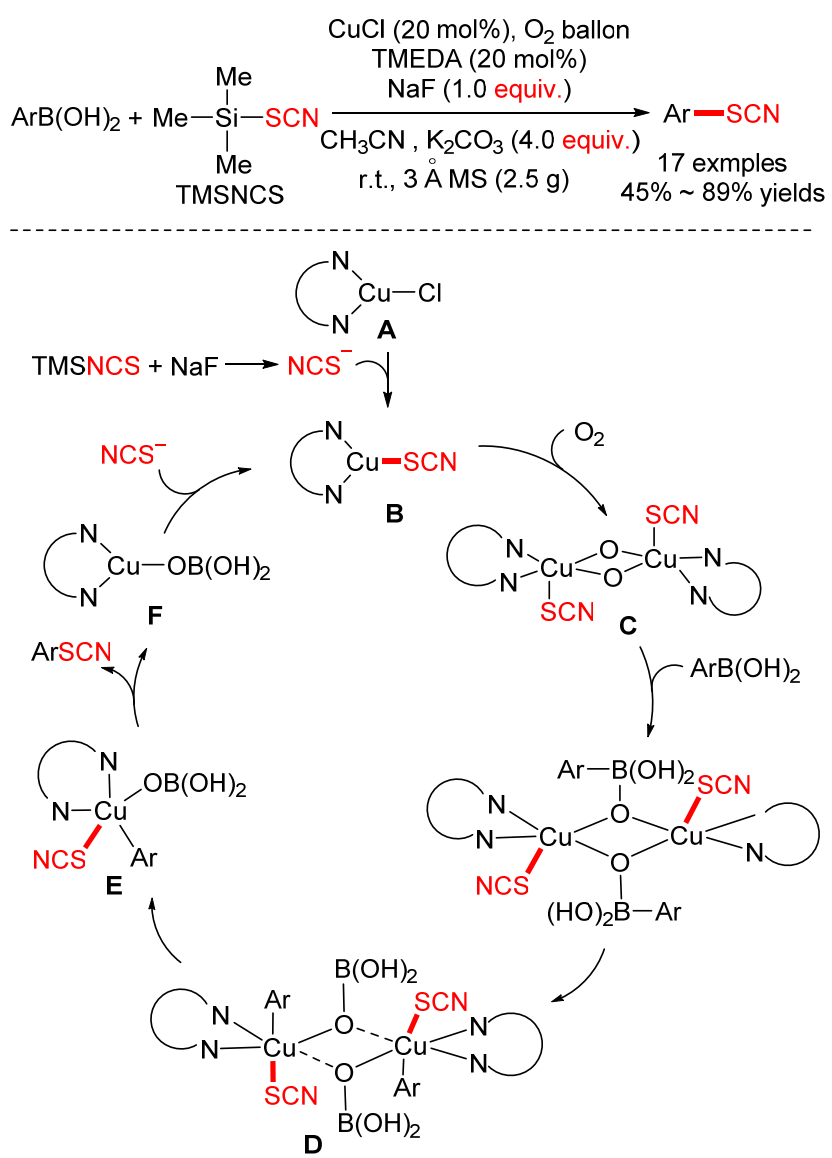

图式 1 芳基硼酸和 TMSNCS 的硫氰化反应

Scheme 1 Thiocyanation of arylboronic acids with TMSNCS

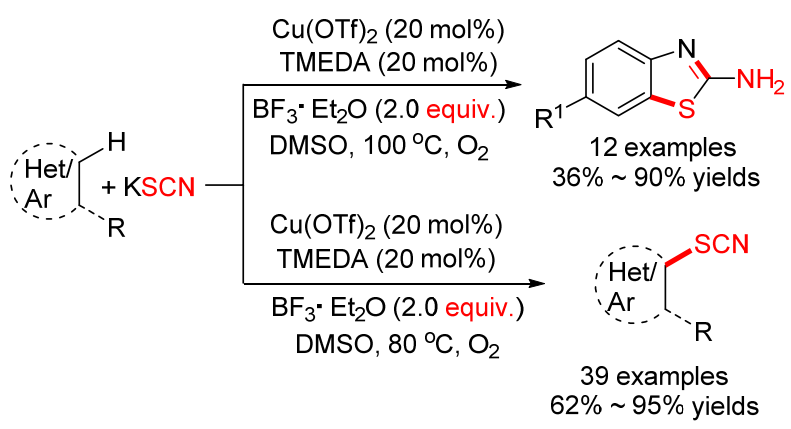

图式 2 铜催化(杂)芳环化合物的硫氰化反应

Scheme 2 Copper-catalyzed thiocyanation of aromatics/heteroaromatics

当以 4-取代的苯胺为原料时，会得到 2-氨基苯并噻唑类 化合物。

2018 年, Zhu 等 ${ }^{[16]}$ 以乙腈作为溶剂, 过硫酸钠为氧 化剂, 硫氰化钠作硫氰源, 经钯催化实现 2-氨基呋喃特 定位点 $\mathrm{sp}^{3}-\mathrm{C}-\mathrm{H}$ 键硫氧化反应( Eq. 2). 该方法条件温 和，底物适用范围广，反应原子经济性较高.

随着绿色环保理念的深入，化学家们开发了一系列 无需过渡金属催化剂、采用清洁能源的绿色合成新路线, 为硫氰酸酯的合成注入了新活力. 2016 年, $\mathrm{Rad}^{[17]}$ 在 


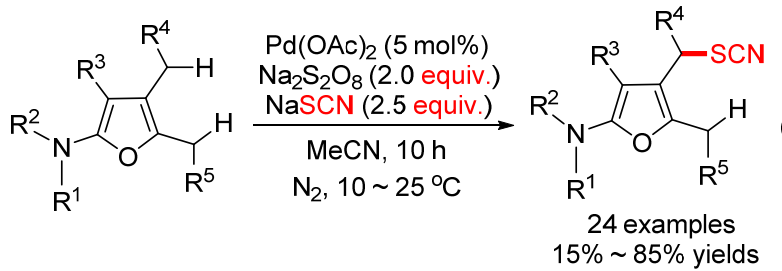

$N$-(对甲苯磺酰基)咪唑(TsIm)环境中实现了醇的硫氰化 反应，合成了一系列烷基硫氰酸酯(Eq. 3). 在 $70{ }^{\circ} \mathrm{C}$ 无 水 $N, N$-二甲基甲酰胺(DMF)中, 以三乙胺作碱, 加入少 量 TsIm, 经 6 12 h 后能以最高 $95 \%$ 的收率完成反应. 值得一提的是, 该方法具有良好的选择性, 即使有仲醇 存在，硫氰化钾也能与伯醇特定结合.

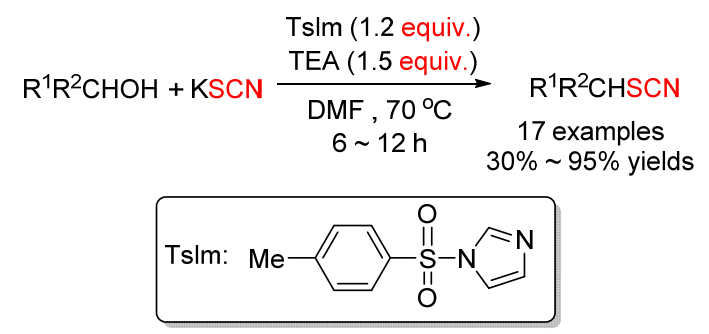

2017 年, Reddy 等 ${ }^{[18]}$ 在 $70{ }^{\circ} \mathrm{C}$ 的醋酸溶剂中, 实现 了硫氰化钾与炔酮的选择性硫氰化反应, 以良好到优异 的收率分离得到硫氰化产物. 升高温度并延长反应时 间, 硫氰化烯酮可发生分子内环化得到噻嗪-2-硫酮衍 生物(Scheme 3). 该方法的底物适应性较好, 且收率不 错.

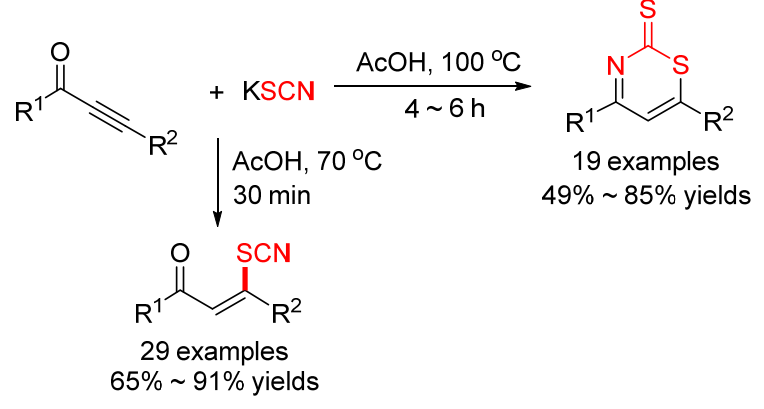

图式 3 炔酮的硫氰化反应和分子内环化反应

Scheme 3 Thiocyanation of ynones and concomitant intramolecular cyclizations

另外, Patel 课题组 ${ }^{[19]}$ 使用异硫氰化物充当硫氰化亲 核试剂，实现了一种甲基咪唑促进的酮类化合物 $\alpha$-位硫 氯化反应(Eq. 4). 之后 2017 年, 该课题组 ${ }^{[20]}$ 研究发现仅 需催化量的甲基咪唑就可实现环氧乙烷的硫氰化酯化 反应(Scheme 4), 反应条件温和, 原子利用率 $100 \%$, 收 率在 $75 \% \sim 92 \%$, 底物普适性也很好.

Yadav 课题组 ${ }^{[21]}$ 以 Eosin Y 作光催化剂, 在绿光的

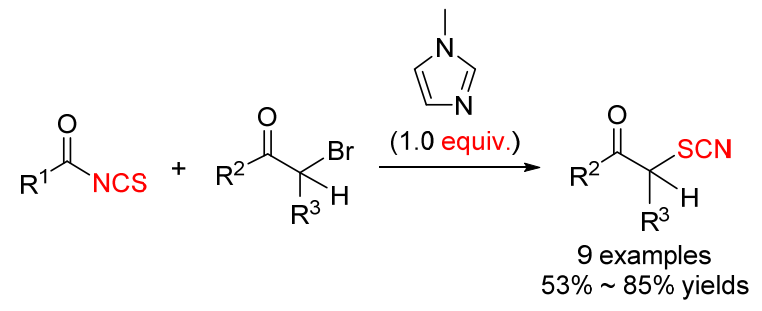

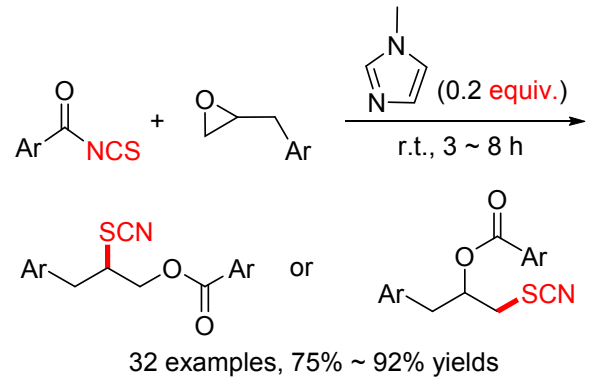

图式 4 有机催化环氧乙烷的硫氧化酰化反应 Scheme 4 Organocatalytic thiocyanation and acylation of oxiranes

照射下促进叔胺 $\alpha$ 位的硫氰化反应. 该方法仅需要 1 mol\% 的 Eosin Y, 在空气氛围中, 室温下搅拌反应 $6 \sim 10$ $h$, 就可以 $74 \% \sim 95 \%$ 的收率获得一系列硫氰化四氢异 喹啉产物. 他们提出了一种可能的机理: (1) EY 吸收光 能进入激发态 $\left(\mathrm{EY}^{*}\right)$; (2) 原料和 $\mathrm{EY} *$ 之间进行单电子转 移得到 $\mathbf{A}$ 和 $\mathrm{RB}^{\cdot-}$; (3)氧气氧化 $\mathrm{RB}^{\cdot-}$ 得到基态 $\mathrm{EY}$, 并产 生 $\mathrm{O}_{2}{ }^{--}$; (4) $\mathrm{O}_{2}{ }^{-}$从 $\mathbf{A}$ 的 $\alpha$ 位瞳取质子, 形成亚胺离子 $\mathbf{B}$; (5) B 受到 ${ }^{-} \mathrm{SCN}$ 的进攻, 得到最终产物(Scheme 5).

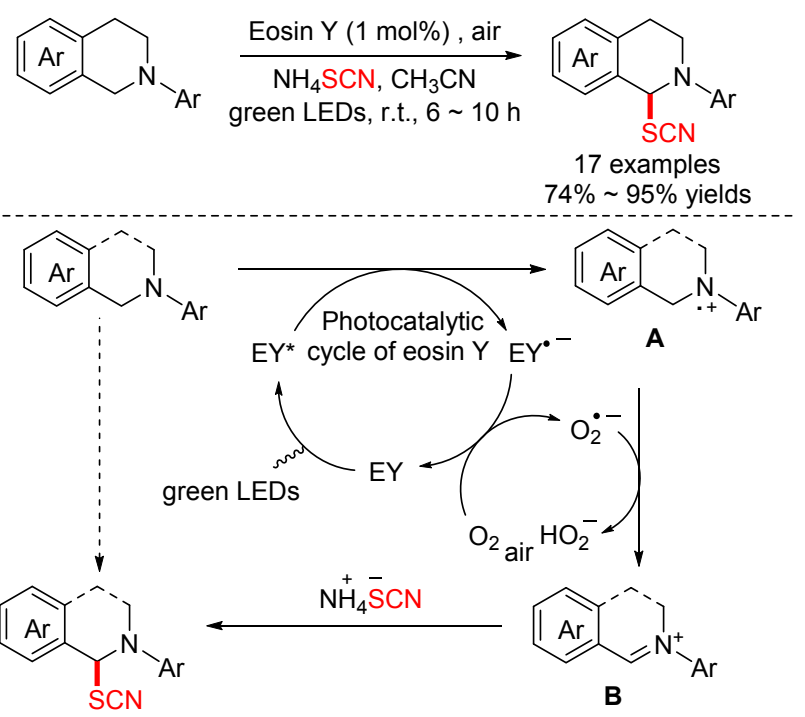

图式 5 叔胺 $\alpha-\mathrm{C}\left(\mathrm{sp}^{3}\right)-\mathrm{H}$ 硫氰化

Scheme $5 \alpha-\mathrm{C}\left(\mathrm{sp}^{3}\right)-\mathrm{H}$ thiocyanation of tertiary amines

2018 年, Bolm 课题组 ${ }^{[22]}$ 合成一种新型的 $N-S C N$ 亚 砜亚胺试剂, 并很好地将其应用于烯烃的双官能团化反 
应中(Eq. 5). 在二氯甲烷(DCM)溶剂中, $N-\mathrm{Br}$ 亚砜亚胺 与 $\mathrm{NH}_{4} \mathrm{SCN}$ 在常温下反应 $16 \mathrm{~h}$ 便可制得这种新型硫氰 化试剂. 以 $\mathrm{Ir}$ 为催化剂, 在蓝光照射下, 该试剂能与烯 烃以 $38 \% \sim 81 \%$ 的收率反应得到一系列新颖的硫氰化亚 胺化产物.

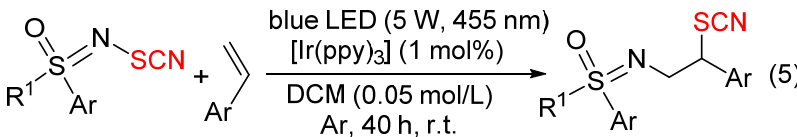

$$
\begin{aligned}
& 24 \text { examples } \\
& 38 \% \sim 81 \% \text { yields }
\end{aligned}
$$

同年, Liang 等 ${ }^{[23]}$ 以非均相固体盐 Amberlyst-15(H) $[\mathrm{A}-15(\mathrm{H})]$ 为质子催化剂, 采用恒电流电解的方法来合 成有机硫氧化物(Eq. 6). 值得一提的是, 这种电化学氧 化硫氰化路径无需添加外部导电盐, 并且固体盐可以重 复使用多达五次，效率没有显著降低.

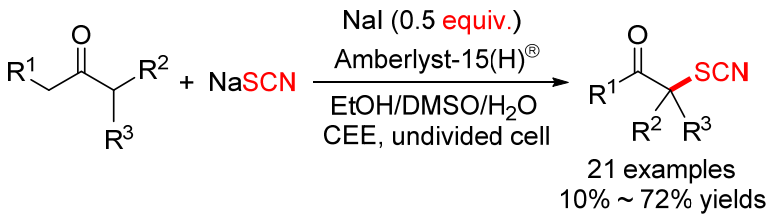

\section{1 .2 亲电取代}

富电子芳环与硫氰化亲电试剂发生亲电取代反应 是在芳香化合物中引入硫氰根官能团比较实用的方法, 现已开发出多种新型亲电硫氰化体系. 较为经典的是氯 代琥珀酰亚胺(NCS)和硫氰酸盐体系, NCS 与硫氰酸盐 反应生成的中间体硫㲵代琥珀酰亚胺(NTS) 是关键的亲 电硫氰源. 2016 年, Besset 小组 ${ }^{[24]}$ 报道了一种 NCS 促进 下的苯胺 $\mathrm{N}$ 原子上引入硫氰根的新方法(Eq. 7). 以四氢 呋喃(THF)为溶剂和硫氰酸银作硫氰源, 在温和的条件 下以 $71 \% \sim 87 \%$ 收率获得目标产物.

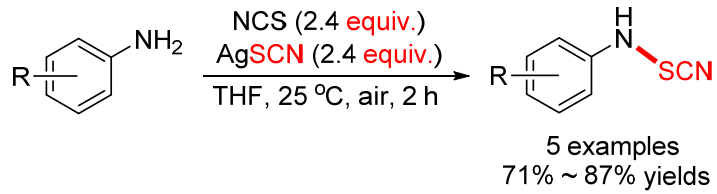

Wang 等 ${ }^{[25]}$ 于 2016 年提出了一锅两步法合成 3-氰硫 基咪唑并 $[1,2-a]$ 吡啶(Scheme 6). 他们使用商业化的溴 代苯乙酮与 2-氨基吡啶为原料在乙醇中反应得到中间 产物 2-苯基咪唑并 $[1,2-a$ ]吡啶, 随后经硫氰化亲电取代 反应，以 $64 \%$ ～90\%的收率合成得到一系列硫氧化咪唑 并 $[1,2-a]$ 吡啶类化合物. 该方法简单快速，对环境友好 且易于实施，为这类硫氰(酸酯的简便合成提供新思路.

2017 年, Wang 小组 ${ }^{[26]}$ 报道了氯代琥珀酰亚胺(NCS)
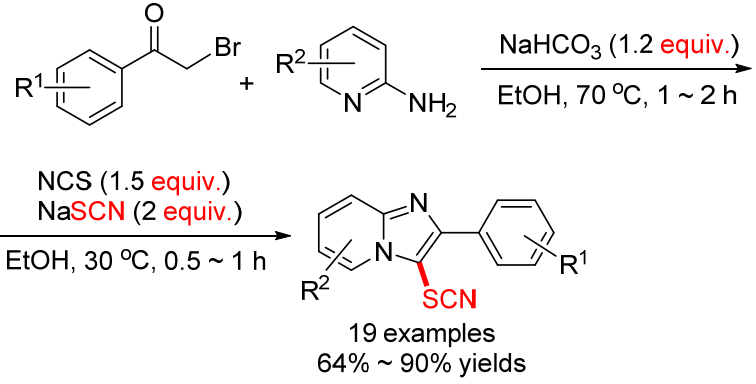

图式 6 一锅法制备咪唑并吡啶硫氰酸酯

Scheme 6 Thiocyanation of imidazopyridines in a sequential one-pot process

促进下的烯酮二硫缩醛的直接硫氰化反应. 该小组对反 应机理进行了推测: (1) $\mathrm{NCS}$ 和 $\mathrm{NH}_{4} \mathrm{SCN}$ 反应生成硫氰 代琥珀酰亚胺(NTS); (2)烯酮二硫缩醛与 NTS 结合, 得 到中间体 $\mathbf{A}$ 和 $\mathbf{B}$; (3) $\mathbf{A}$ 和 $\mathbf{B}$ 作用, 经去质子化得到目标 产物(Scheme 7).
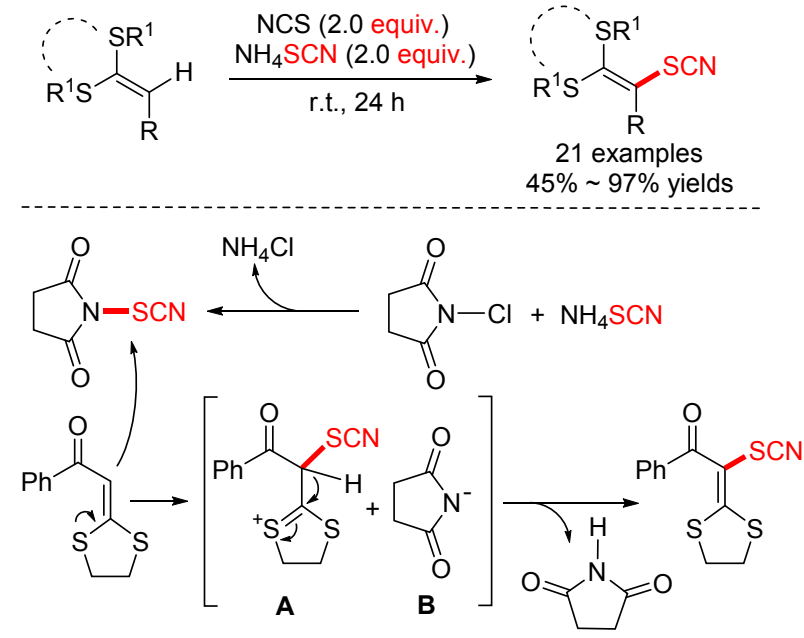

图式 7 乙烯二硫代缩醛的硫氰化反应

Scheme 7 Thiocyanation of ketene dithioacetals

众所周知, 1,1,1,3,3,3-六氟-2-丙醇(HFIP)在有机中 作为一种绿色溶剂而倍受欢迎，并且它具有一些独特的 性质, 如低亲核性、高离子化能力等. Wang 课题组 ${ }^{[27]}$ 认 为 HFIP 可以通过氢键结合激活 NCS, 从而促进了 $\mathrm{N}-$ $\mathrm{Cl}$ 键的裂解而形成 CISCN. 该课题组发现, 在超声辅助 下, 在 HFIP 溶剂中, NCS 和硫氰酸铵能与富电子芳烃 (苯酚、苯胺或吲哚)发生硫氰化反应(Scheme 8). 反应只 需 5 30 min, 即可以最高 99\%的收率得到目标产物.

此外，其他亲电硫氰化体系也有报道. 2016 年, Rajanna 等 ${ }^{[28]}$ 在室温下的二氯甲烷溶剂中, 以三聚氭氯 (TCTA)作氯化剂，实现了(杂)芳环的硫氧化取代反应 (Scheme 9). 对比发现反应在超声辅助下, 可平稳且快 速地完成, 并能以良好到优异的收率得到产物. 

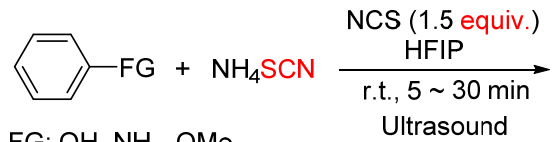

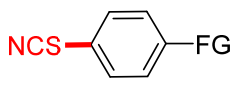

FG: $\mathrm{OH}, \mathrm{NH}_{2}, \mathrm{OMe}$

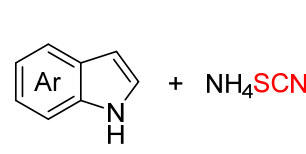

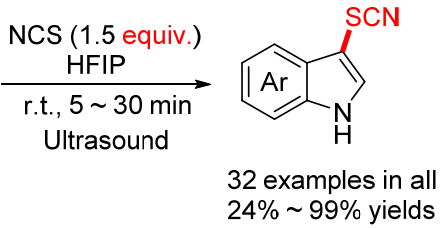

图式 8 超声辅助下苯酚、苯胺和吲哚的硫氰化反应

Scheme 8 Ultrasonic assisted thiocyanation of phenols, anilines and hydrazines

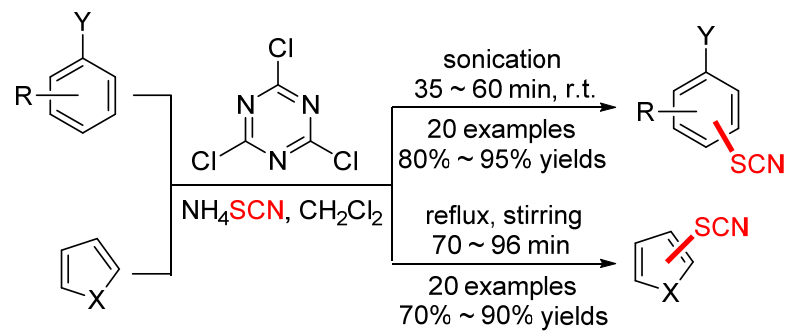

$\mathrm{X}=\mathrm{NH}, \mathrm{O}, \mathrm{S} ; \mathrm{Y}=\mathrm{H}, \mathrm{OH}, \mathrm{NH}_{2}$ etc.; $\mathrm{R}=\mathrm{EWG}, \mathrm{EDG}$

图式 9 三聚氰氯/ $\mathrm{NH}_{4} \mathrm{SCN}$ 促进的芳烃硫氰化反应 Scheme 9 Cyanuric chloride/ $\mathrm{NH}_{4} \mathrm{SCN}$ triggered thiocyanation of aromatic compounds

2018 年, Chen 小组 ${ }^{[29]}$ 就 $\beta$-酮羰基化合物的不对称 硫氰酸酯化提出一条新路径. 他们以 $N$-硫氰基邻苯二 甲酰亚胺为硫氰化亲电试剂, 在金鸡纳生物碱的催化下 完成底物不对称 $\alpha$-硫氰酸酯化反应(Eq. 8). 可反应的底 物种类较多，且大部分产物的收率都在 $90 \%$ 以上. 同时 方法具有高对映体选择性, 实现合成具有季碳中心的各 种手性 $\alpha$-氰硫基 $\beta$-酮酯, 但反应需在 $-78{ }^{\circ} \mathrm{C}$ 下进行.

最近, Chen 课题组 ${ }^{[30]}$ 以甜味添加剂糖精为原料, 分<smiles>[R]OC([R])C1C(=O)c2ccc([R1])cc2C1=O</smiles>

$n=1,2,3$

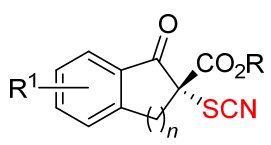

15 examples $36 \% \sim 99 \%$ yields

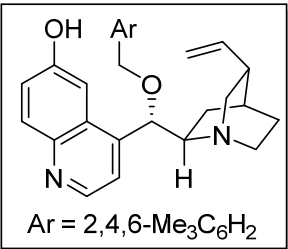

(8)

两步合成一种新型的硫氧化亲电试剂. 首先将糖精和次 氯酸叔丁酯在甲醇中处理 $5 \mathrm{~min}$, 得到 $N$-氯代糖，随后 其与 $\mathrm{AgSCN}$ 在 $\mathrm{CH}_{2} \mathrm{Cl}_{2}$ 溶剂中反应 $30 \mathrm{~min}$ 可得到 $N$-硫 氧酸基糖精. 他们研究发现这种新硫氧化试剂能很好用 于吲哚类、羟吲哚类、酚类、 $\beta$-酮羰基化合物, 芳香胺 类和芳香酮等化合物的硫氧化反应，并且表现出较为优 异的反应性能(Scheme 10).

\section{1 .3 自由基反应}

自由基硫氰化反应是合成有机硫氰化物的一种重 要途径, 传统的反应中通常需要加入过量的氧化剂, 如 过硫酸盐、醋酸锰、硝酸铈铵等促进反应发生. 2015 年 Guo 等 ${ }^{[31]}$ 开发了一种无需金属催化的烯烃酰胺与硫氰 酸钾的串联硫氰化/分子内环化反应. 以容易获得烯烃 酰胺为原料, 在温和的条件下通过一步反应构建 $\mathrm{C}-\mathrm{O}$ 和 $\mathrm{C}-\mathrm{S}$ 键, 调控酰胺底物, 可以分别得到苯并六元杂 环和苯并五元杂环. 该课题组对反应机理进行了阐述: (1) $\mathrm{K}_{2} \mathrm{~S}_{2} \mathrm{O}_{8}$ 氧化硫氰根阴离子产生硫氰根自由基 $\mathbf{A}$; (2) A 加成到原料的碳碳双键上并产生 $\mathbf{B}$; (3) B 进行自由基 环化得到 $\mathbf{C}$; (4)氧化剂将自由基 $\mathbf{C}$ 进一步氧化成相应的 碳正离子，其经去质子化得到产物(Scheme 11).

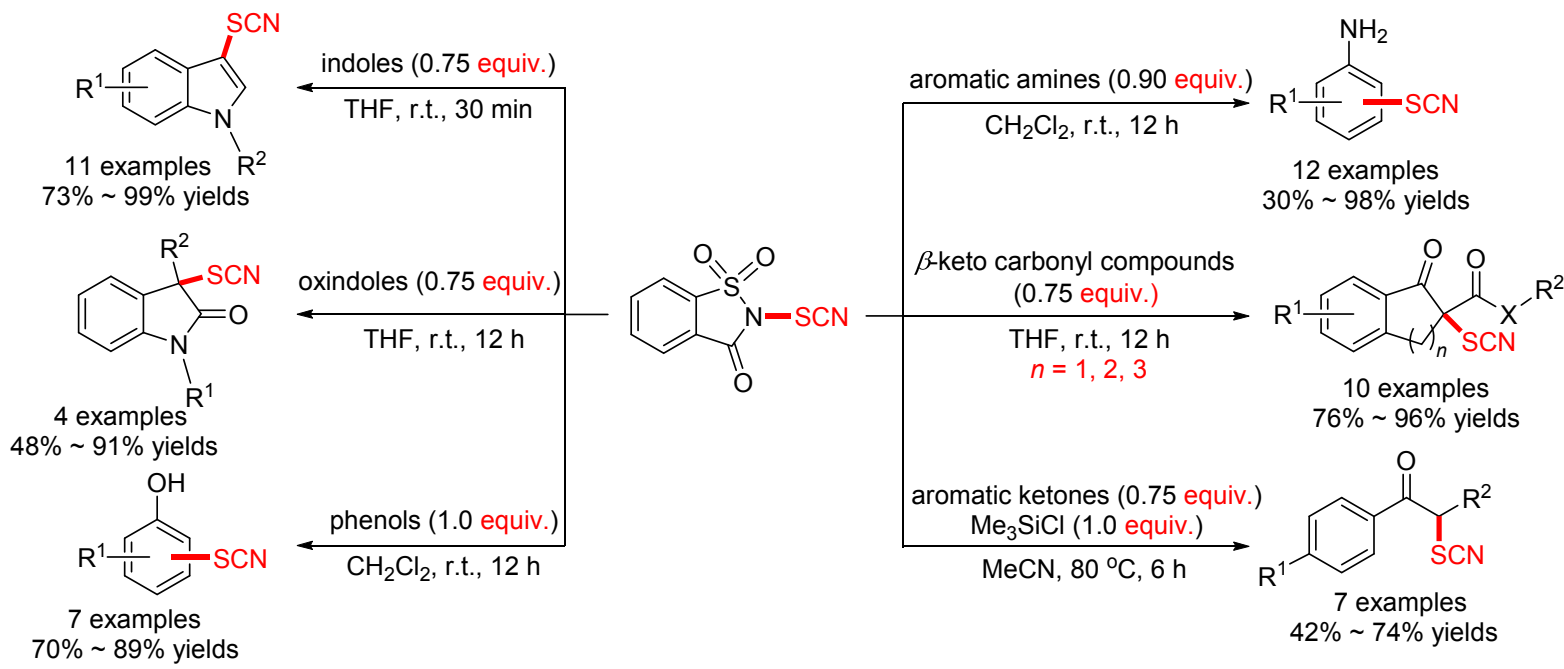

图式 $10 N$-硫氰化糖精的应用

Scheme 10 Applications of $N$-thiocyanatosaccharin 

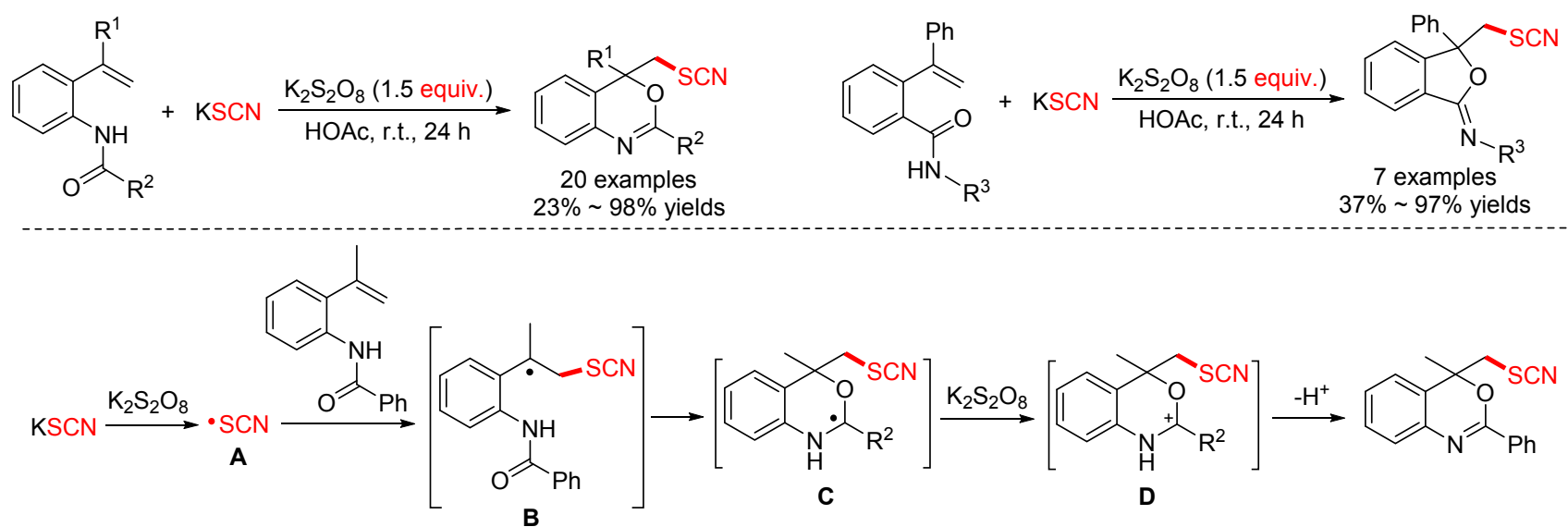

图式 11 烯烃酰胺的硫氰化/环化反应

Scheme 11 Thiocyanation/cyclization of olefinic amides

2015 年, Wang 课题组 ${ }^{[32]}$ 报道了一种咪唑并吡啶硫 氰化的方法. 在室温下, 1,2-二氯乙烷(DCE)溶剂中, 以 过硫酸钾为氧化剂, 硫氰化钾作硫氰源, 实现 C-3 位硫 氰化咪唑并吡啶的有效合成. 此外, 该方法也能很好地 应用于其他杂环和芳香族(咪唑并 $[2,1-b]$ 噻唑、吲哚和 $N, N$-二甲基苯胺)的硫氰化反应. 对此过程他们提出了 两条可能的途径: 路径 a: (1)首先 $\mathrm{KSCN}$ 被氧化产生 - $\mathrm{SCN}$ 自由基 $\mathbf{A}$; (2) $\mathbf{A}$ 与咪唑并吡啶反应得到自由基 $\mathbf{C}$; (3) $\mathrm{C}$ 被 $\mathrm{K}_{2} \mathrm{~S}_{2} \mathrm{O}_{8}$ 进一步氧化成碳正离子 D; (4) D 去质子 化得到硫氰化产物. 路径 b: (1) $\mathrm{K}_{2} \mathrm{~S}_{2} \mathrm{O}_{8}$ 与 $\mathrm{KSCN}$ 产生一 种亲电子的二硫氰化物 $(\mathrm{SCN})_{2} ;(2) \mathbf{B}$ 与咪唑并吡啶进行 亲电加成产生 $\mathbf{D}$, 随后失去质子生成产物(Scheme 12).

$\mathrm{Yu}$ 小组 ${ }^{[33]}$ 于 2016 年发现在室温下的 DCE 溶剂中, 以过硫化钾为氧化剂, 烯胺酮与硫氰化钾顺利进行硫氰 化/环化反应(Eq. 9). 他们认为烯胺中的二甲基氨基可作 活化基团, 可促进硫氰化过程, 并在环化过程中作为离 去基团离去.

2016 年, Guo 等 ${ }^{[34]}$ 报道了一种在无过渡金属催化的 烯烃硫氰化/环化反应(Scheme 13). 这种串联分子间硫

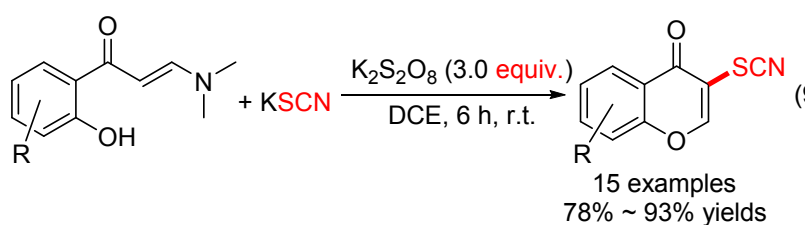

氰化和分子内环化的过程，为合成含有硫氰基团的二氢 呋喃和内酯化合物提供了一种易于操作，原子经济好, 收率高的新方法. 但是他们发现当 $\mathrm{R}$ 为不同取代的苯环 时，空间位阻效应对反应收率有较大影响.

2017 年, $\mathrm{Xu}$ 等 ${ }^{[35]}$ 开发了一种铜催化 8-氨基喹啉衍 生物的硫/硒氰化反应(Eq. 10). 优化条件时他们发现以 $1,2-$ 二氯乙烷 $(\mathrm{DCE})$ 为溶剂, $\mathrm{KSCN} / \mathrm{KSeCN}$ 作为硫/硒氰 化试剂，过硫酸钾作氧化剂的条件下，反应收率表现较 为一般. 但加入少量相转移催化剂四丁基碘化铵(TBAI) 可有效提高收率.

2017 年, Bhat 课题组 ${ }^{[36]}$ 开发了一种过硫酸钾氧化下 直接用于苯酚、苯胺和吲哚、噻吩等杂环的硫氰化路径 (Scheme 14). 他们利用 DCM 为溶剂, 过硫化钾作氧化 剂, 在温和条件下实现了上述芳香化合物的高效硫氧化

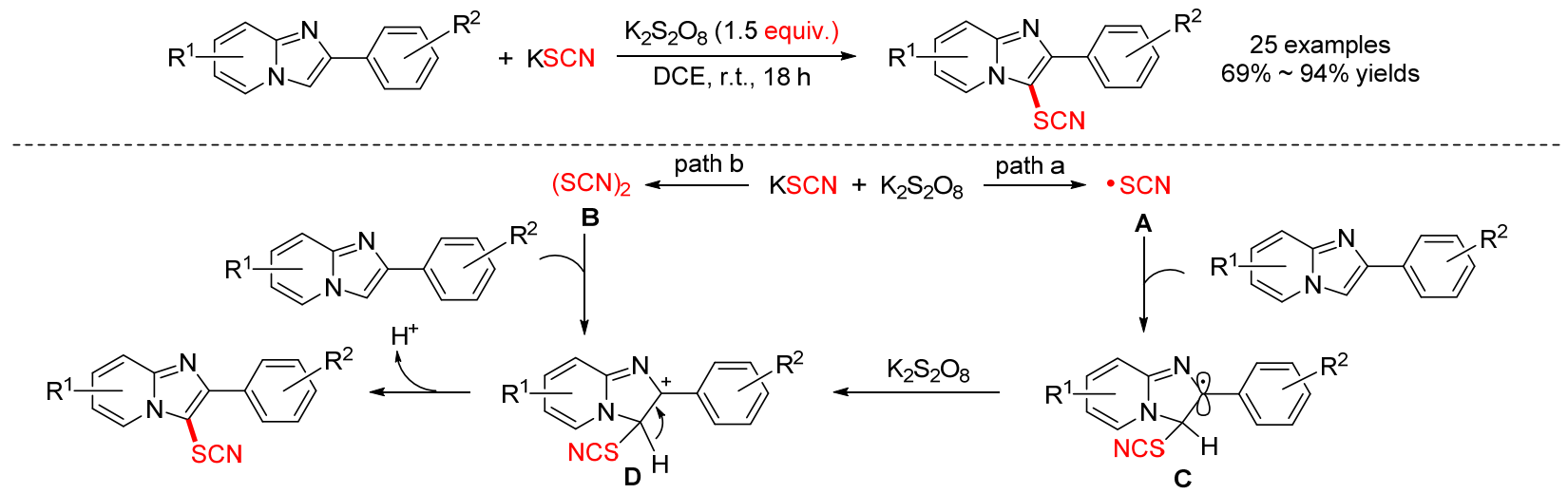

图式 12 咪唑并吡啶的硫氰化反应

Scheme 12 Thiocyanation of imidazopyridines 


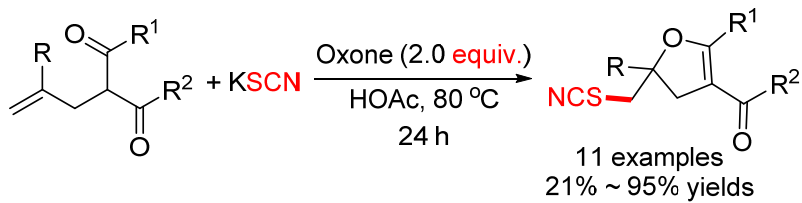

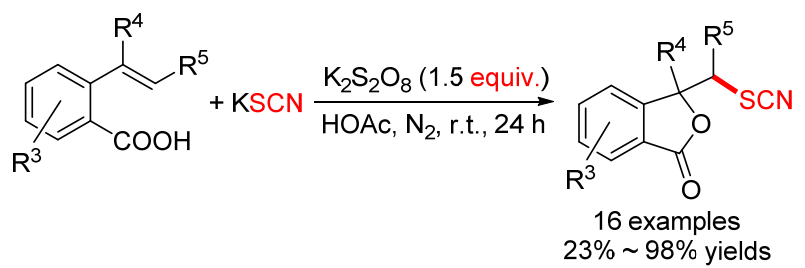

图式 13 烯烃的硫氧化/环化反应

Scheme 13 Thiocyanation / cyclization of olefins

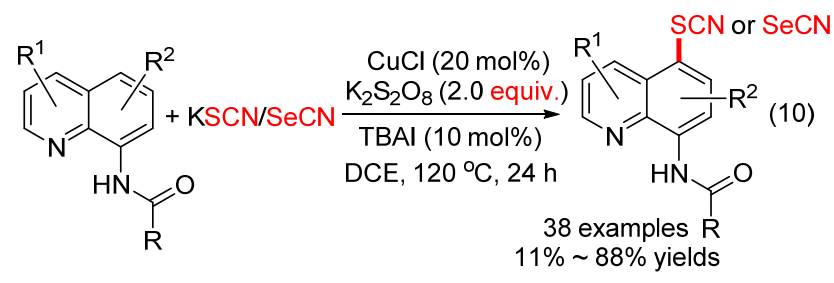

反应.

$$
\begin{array}{ll}
\text { r.t., } \mathrm{DCM}, 4 \mathrm{~h} \\
\mathrm{FG}=\mathrm{OH}, \mathrm{OMe}, \mathrm{NH}_{2}
\end{array}
$$

图式 14 苯酚、苯胺和杂环区域选择性的硫氰化 Scheme 14 Regioselective thiocyanation of phenols, anilines and heterocycles

含硫氰基团的杂环化合物具有一定药理活性, 这类 化合物通常是杂环直接硫氰化得到, 最近科学家们开发 出了一种串联硫氰化/环化的方案来制备含硫氰基团的 杂环化合物. $\mathrm{Li}$ 等 ${ }^{[37]}$ 于 2017 年发展了一种以铁为催化 剂和过硫酸钾作氧化剂, 在氩气保护下合成硫氰化惡唑 啉的新方法(Eq. 11). 他们利用 $\beta, \gamma$-不饱和肜的硫化/环 化过程, 实现特定位点以最高 $84 \%$ 的收率引入硫氰基 才.

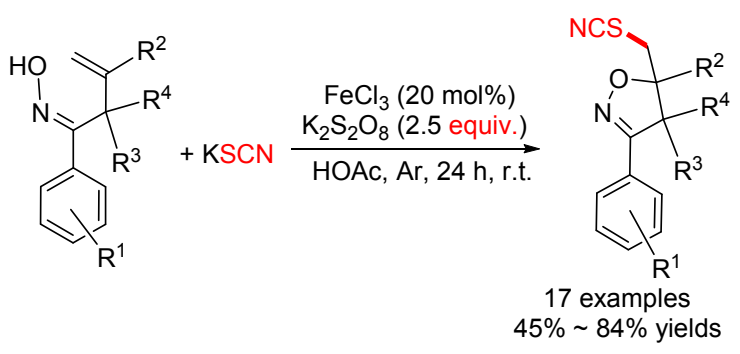

2018 年, Chen 小组 ${ }^{[38]}$ 报道了一种硫氰化银为原料
的 $N$-芳基丙烯酰胺的硫氰基自由基加成环化反应，最 高能以 91\%的收率合成 3-硫氰甲基化-2-吲哚酮类化合 物(Eq. 12). 该方法条件温和, 底物适用性范围广, 但使 用硫氰化银作为硫氰化试剂, 合成成本较高.

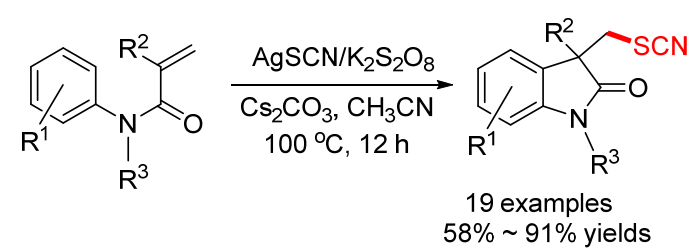

Wang 小组 ${ }^{[39]}$ 开发了一种合成 3-硫氰基香豆素的新 方法(Eq. 13). 在二甲基亚砜(DMSO)溶剂中，以硝酸铈 铵 $\left[\mathrm{Ce}\left(\mathrm{NH}_{4}\right)_{2}\left(\mathrm{NO}_{3}\right)_{6}\right]$ 作氧化剂, 实现硫氰酸银与 3-苯基 丙炔酸苯酯的自由基环化反应. 采用硫氰酸银作为硫氰 化试剂, 合成成本较高, 而且产品的收率也表现较为一 般.

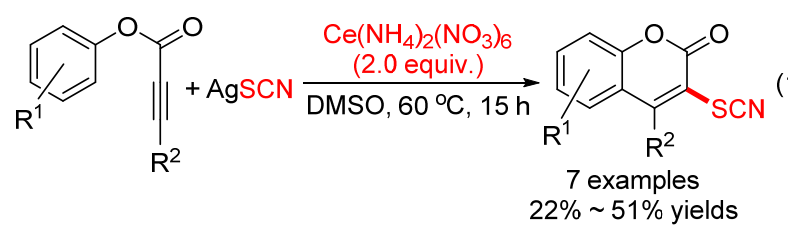

2016 年, Lv 小组 ${ }^{[40]}$ 实现了铜催化下苯乙烯的双硫 氭化反应. 在二氯甲烷溶剂中, 以 Selectfluor 为氧化剂, 加热回流，反应能以中等到良好的收率得到目标产物. 由于二硫氰酸酯类化合物显示出良好的抑制真菌活性， 合成这类化合物的方法也备受关注，该方法为二硫氰酸 酯类化合物的合成提供了新途径. 他们对反应机理进行 了推测: (1)在 $\mathrm{CuBr}$ 存在下, 由 Selectfluor 氧化硫氰根阴 离子产生硫氰酸根自由基 $\mathbf{A}$; (2) $\mathbf{A}$ 加成到苯乙烯上产生 以自由基 $\mathbf{B}$; (3)其进一步氧化成碳阳离子 $\mathbf{C}$; (4) $\mathrm{SCN}^{-}$与 C 进行亲核反应形成的产物(Scheme 15).
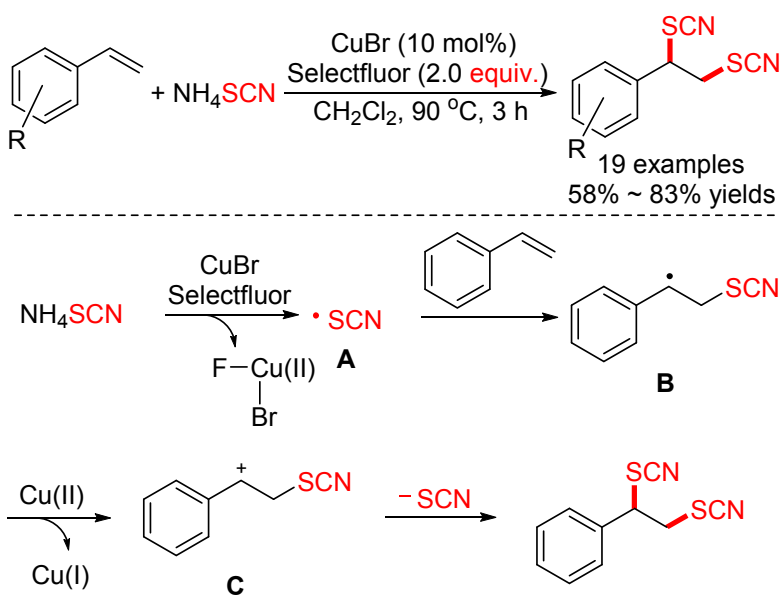

图式 15 铜催化苯乙烯的二硫氰化反应

Scheme 15 Copper-catalyzed dithiocyanation of styrenes 
2018 年, Zhang 课题组 ${ }^{[41]}$ 开发了一种烯烃硫氰化膦 酰化反应(Eq. 14). 以铜作催化剂和醋酸锰为氧化剂, 实 现二苯基酰膦和 TMSNCS 与烯烃的自由基加成反应. 机理实验表明烯烃首先与膦酰基自由基进行加成, 之后 在铜催化下完成硫氰化. 该方法条件温和, 底物普适性 好, 链状烯烃和环状烯烃都能很好地完成反应, 得到相 应产物。

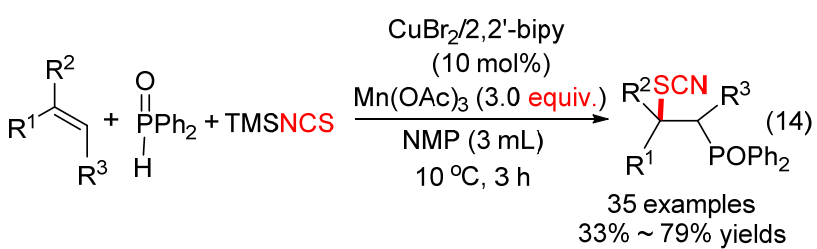

近几年来, 化学家们又发展了一系列高效节能的光 催化硫氰化反应，相对于传统的自由基硫氰化反应，这 类反应可以直接以空气为氧化剂, 更为绿色环保. $\mathrm{Li}$ 课 题组 $^{[42]}$ 于 2014 年提出了一种可见光促进吲哚 $\beta$ 位引入 硫氰基策略. 使用廉价易得的 Rose Bengal 作光催化剂, 以四氢呋喃为溶剂, 经白光照射 $24 \mathrm{~h}$ 后完成吲哚的硫氰 化反应. 该小组对反应机理进行了推测: (1)经可见光照 射, Rose Bengal 转变成激发的 $\mathrm{RB}^{*}$; (2) ${ }^{-} \mathrm{SCN}$ 和 $\mathrm{RB} *$ 之

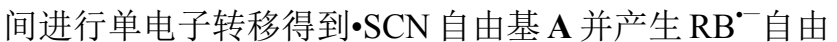
基阴离子; (3)氧气氧化 $\mathrm{RB}^{\cdot-}$ 得到基态 Rose Bengal; (4) A 和吲哚进行亲电加成, 得到中间体 $\mathbf{B}$; (5) $\mathbf{B}$ 被氧化后产 生阳离子 $\mathbf{C}$; (6) $\mathbf{C}$ 失去质子最终得到产物(Scheme 16).
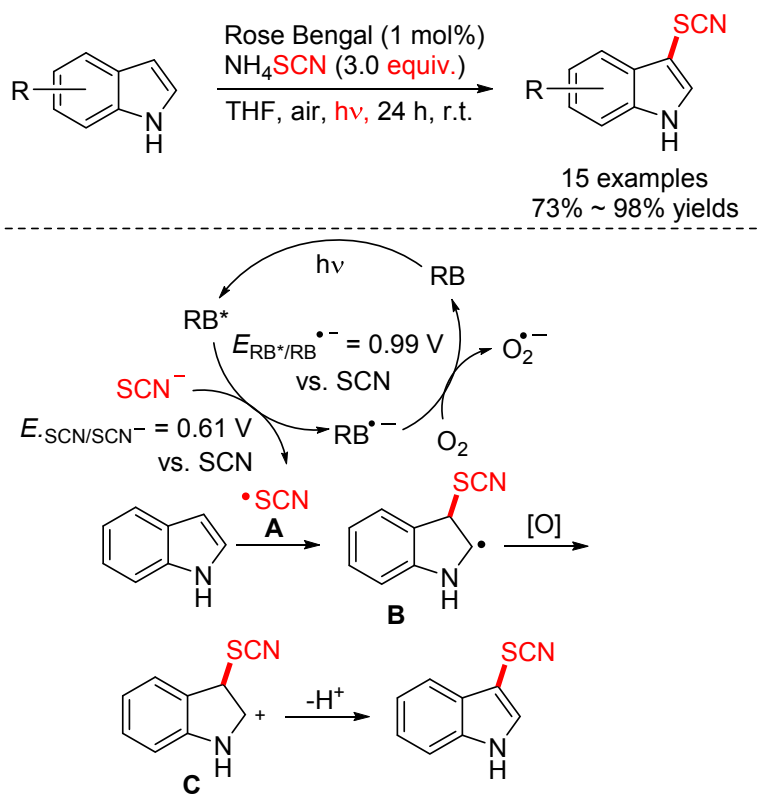

图式 16 可见光促进吲哚的硫氰化反应

Scheme 16 Visible-light-promoted thiocyanation of indoles

2015 年, Hajra 等 ${ }^{[43]}$ 报道了蓝光照射 Eosin Y 催化咪 唑杂环的硫氧化反应(Eq. 15). 在空气和室温下的乙腈 溶剂中, 通过蓝光催化实现 $\mathrm{NH}_{4} \mathrm{SCN}$ 与原料的反应. 底
物拓展研究表明，该方法可以高产率合成具有广泛官能 团的 3-硫氰基咪唑并 $[1,2-a$ 吡啶类化合物，底物上无论 有强供电子基还是吸电子基，都能很好地适应该体系顺 利完成.

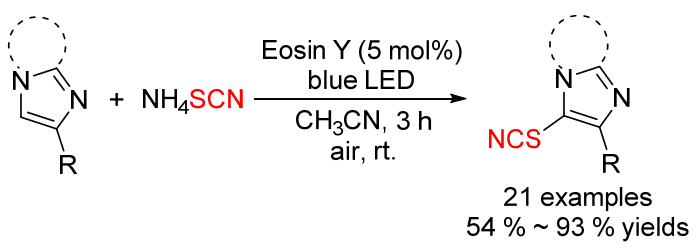

2016 年 $\mathrm{He}$ 小组 ${ }^{[44]}$ 采用 $\mathrm{TiO}_{2} / \mathrm{MoS}_{2}$ 纳米材料为复合 光催化剂, 催化吲哚的硫氧化反应(Eq. 16). 大部分底物 收率表现良好，当有底物有吸电子基团存在时，则收率 较差. 催化剂的可重复使用性是本方法的一大优点.

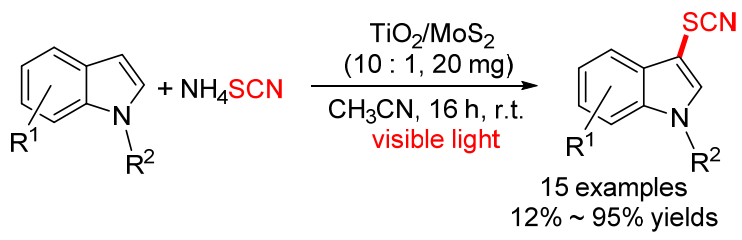

Singh 等 ${ }^{[45]}$ 于 2018 年以 Eosin $\mathrm{Y}$ 为光催化剂, 以异 腈和硫氰酸铵为原料, 在乙腈溶剂中, 经绿光照射 8 $16 \mathrm{~h}$ 后合成了一系列 6-硫氰菲啶类化合物(Eq. 17). 不 同异腈底物均能较好地适用该反应条件，产物收率最高 可达 94\%, 为 6-硫氧菲啶的有效合成提供了新思路.

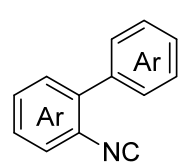

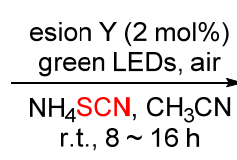

r.t., $8 \sim 16 \mathrm{~h}$

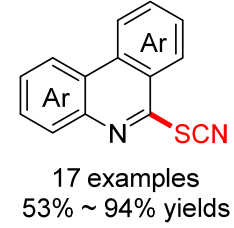

\section{2 间接合成法}

随着直接硫氰化路线的发展，对于不易直接硫氧化 的化合物，化学家们也在尝试间接方法来合成硫氰化 物. 最常见的是通过氰化试剂与含硫底物反应得到硫氰 酸酯.

\subsection{1 亲核取代}

2017 年, Xia 等 ${ }^{[46]}$ 利用过硫酸钠和 1,5 -二氮杂二环 [5.4.0]十一-5-烯(DBU)促进硫酚、硫醇与氰化钠直接发 生氰化反应. 实验结果显示, 各种硫酚和硫醇都可以较 好地参与反应，能以 $31 \% \sim 78 \%$ 收率分离得到相应的硫 氯酸酯类化合物. 他们提出了两种可能机理. 路径 $\mathrm{a}:$ (1) 苯硫酚被 DBU 脱去质子得到 $\mathrm{PhS}^{-}$; (2) $\mathrm{PhS}^{-}$被 $\mathrm{Na}_{2} \mathrm{~S}_{2} \mathrm{O}_{8}$ 氧化得到 $\mathrm{PhS} \bullet$; (3)两分子 $\mathrm{PhS}$ •偶联得到 $\mathrm{PhSSPh}$; (4) 氰 根对 PhSSPh 进行亲核取代反应得到产物. 路径 $\mathrm{b}$ : (1) $\mathrm{Na}_{2} \mathrm{~S}_{2} \mathrm{O}_{8}$ 分解产生的 $\mathrm{SO}_{4}{ }^{-}$篗取 $\mathrm{PhSH}$ 的氢自由基生成 $\mathrm{HSO}_{4}{ }^{-}$和自由基 $\mathrm{PhS} \bullet$; (2)两分子 $\mathrm{PhS}$ •偶联得到 $\mathrm{PhSSPh}$, 
$\mathrm{HSO}_{4}{ }^{-}$被 $\mathrm{DBU}$ 中和; (3) $\mathrm{CN}^{-}$与 $\mathrm{PhSSPh}$ 反应得到产物 (Scheme 17).

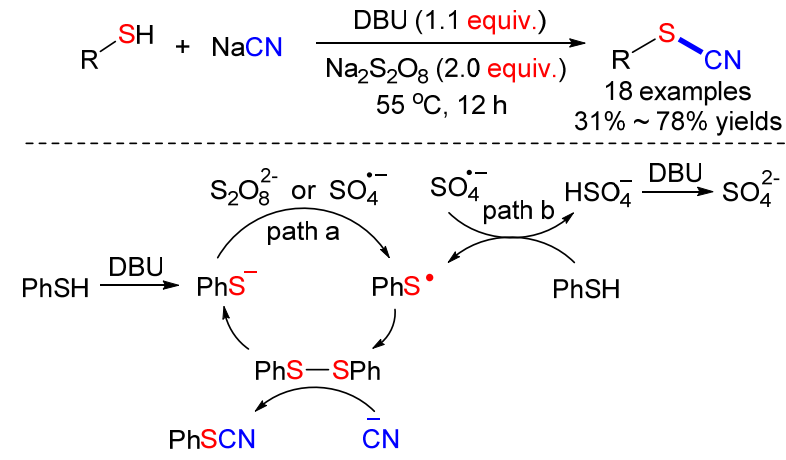

图式 17 硫醇的氰化反应

Scheme 17 Cyanation of thiols

2014 年, Suffert 课题组 ${ }^{[47]}$ 实现了苯硫酚或二芳基二 硫化物的氧化反应. 他们使用氧化亚铜为氧源和氧气作 氧化剂, 在室温条件下进行反应, 产物收率在 $15 \%$ 95\%. 该课题组对机理进行了推测: (1)开始时苯硫酚几 乎瞬时完全转化为二硫化物 $\mathbf{A}$; (2)然后氰化亚铜经氧化 后插入到 S- S 键以形成铜(III)中间体 B; (3)中间体 B 经 历还原消除得到苯基硫氰酸酯以及硫醇铜(I) C; (4)硫醇 铜(I) $\mathbf{C}$ 在氧气作用下生成 $\mathbf{A}$ 和铜(I)完成循环(Scheme 18).
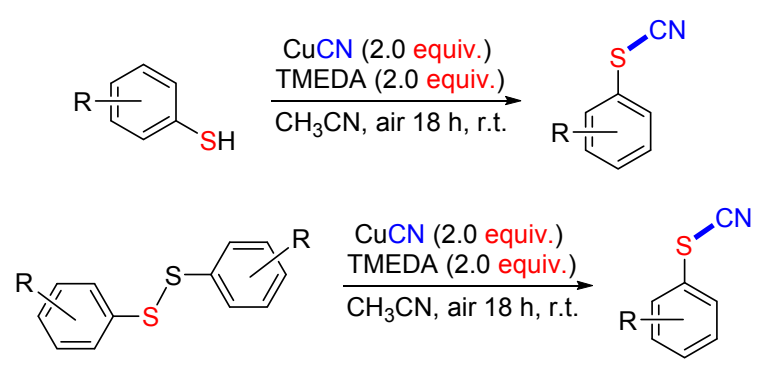

16 examples $15 \% \sim 95 \%$ yields

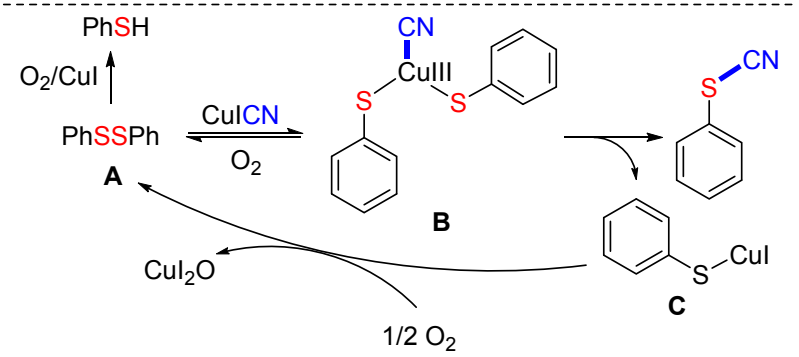

图式 $18 \mathrm{CuCN}$ 与苯硫酚或二芳基二硫化物直接氰化反应

Scheme $18 \mathrm{CuCN}$-mediated cyanation of thiophenols or diaryl disulfides

2018 年, Guo 等 ${ }^{[48]}$ 通过直接可见光催化的 $S-H$ 键 氰化过程, 实现了新型 $\mathrm{C}-\mathrm{S}$ 键断裂和重建, 开发了一 种由无机硫氰酸盐和硫醇合成硫氰酸酯的新策略(Eq. 18). 该反应体系无需金属、碱、配体、无过氧化物等参
与，官能团容忍性好，目标产物收率在 $24 \% \sim 96 \%$ ，反 应放大至克级别, 产品收率也令人满意.

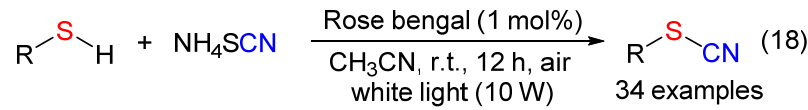

$$
\begin{aligned}
& 24 \% \sim 96 \% \text { yields }
\end{aligned}
$$

1.2.2 亲电取代

2014 年 Waser 等 ${ }^{[49]}$ 使用低毒的 1 -氰基-1,2-苯碘酰3-(1H)酮(CBX)或 1-氭基-3,3-二甲基-3-(1H)-1,2-苯碘酰 (CDBX) 为氧源, 实现了硫醇或二硫化物的氧化反应 (Scheme 19). 在 THF 溶剂中, 以 $\mathrm{CBX}$ 或 CDBX 为亲电 试剂, DBU 作碱, 反应几分钟即可获得各种芳香族、脂 肪族类的硫氰酸酯化合物.

$$
\begin{aligned}
& \stackrel{\mathrm{DBU}(1.1 \text { equiv.) }}{\longrightarrow} \mathrm{R}^{-\mathrm{S}} \mathrm{CN}_{\mathrm{CN}}
\end{aligned}
$$

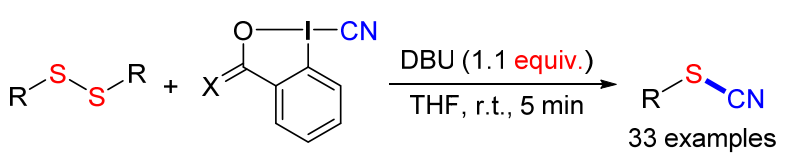

$$
\begin{aligned}
& \mathrm{A}: \mathrm{X}=\mathrm{O}, \mathrm{CBX} ; \mathrm{B}: \mathrm{X}=\mathrm{Me}_{2}, \mathrm{CDBX} \\
& 34 \% \sim 99 \% \text { yields }
\end{aligned}
$$

图式 $19 \mathrm{CBX}$ 或 $\mathrm{CDBX}$ 与苯硫酚或二芳基二硫化物的氧化反 应

Scheme 19 Cyanation of thiophenols or diaryl disulfides with CBX or CDBX

2015 年, Shi 小组 ${ }^{[00]}$ 报道了新型无过渡金属催化的 硫醚的去甲基化氧化反应. 使用较低毒性的芳基(氰基)碘鎓三氟甲磺酸盐为氧源，在氮气保护下，实现了硫醚 与芳基(氧基)碘鈆三氟甲磺酸盐的交叉偶联. 该方法对 芳香硫醚有很好的反应性，而二烷基硫醚反应活性较 差. 该课题组对反应机理进行了推测: (1)芳基(氰基)碘 鎓三氟甲磺酸盐会氧化硫醚会产生中间体 $\mathbf{A}$ 和芳基碘 化物; (2)三氟甲磺酸酯( OTf)与 $\mathbf{A}$ 发生亲核取代反应, 形成产物并释放三氟甲磺酸烷基酯(Scheme 20).

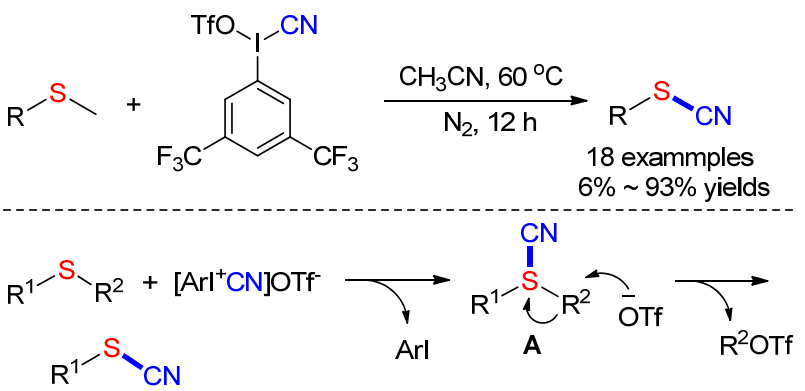

图式 20 硫醚与芳基(氰基)碘鎓三氟甲磺酸盐交叉偶联反应 Scheme 20 Cross-coupling of thioethers with aryl(cyano)iodonium triflates 


\subsection{3 自由基}

Cheng 课题组 ${ }^{[51]}$ 于 2014 年发现以碘化亚铜为催化 剂, 偶氮二异丁腈(AIBN)和二硫化物能发生氰化反应 (Eq. 19). 在乙腈溶剂中, 以碳酸氢钾作碱, 经加热回流 后反应能以良好的收率进行. 值得注意的是, $(\mathrm{ArS})_{2}$ 中 的两个 $\mathrm{ArS}$ 单元在反应中都能使用. 他们认为该反应经 历了自由基历程.

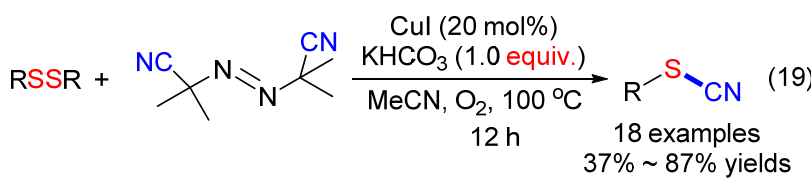

\section{2 .4 其他}

2015 年, Tang 小组 ${ }^{[52]}$ 发现当碘和醋酸钾共同存在 时，硝基甲烷和二硫化物可在 $90{ }^{\circ} \mathrm{C}$ 下发生氰化反应. 使用硝基甲烷作为氰基源代替高毒的氰化试剂，拓宽了 氰化试剂的来源. 他们对反应机理进行了推测: (1)在碘 和 KOAc 存在下二硫化物被氧化成 $\mathbf{A}$; 同时, 碘会与 $\mathrm{MeNO}_{2}$ 反应, 得到碘代硝基甲烷 $\mathbf{B}$ 和 HI; (2) A 与 $\mathbf{B}$ 反 应，生成中间体 $\mathbf{C}$ 和副产物亚磺酸钾(中间体 $\mathbf{C}$ 还有可 能直接由 $\mathrm{MeNO}_{2}$ 与二硫化物的反应形成); (3)中间体 $\mathbf{C}$ 脱水得到 D; (4)通过 HI 还原 $\mathbf{D}$ 得到相应的有机硫氰化 物(Scheme 21).

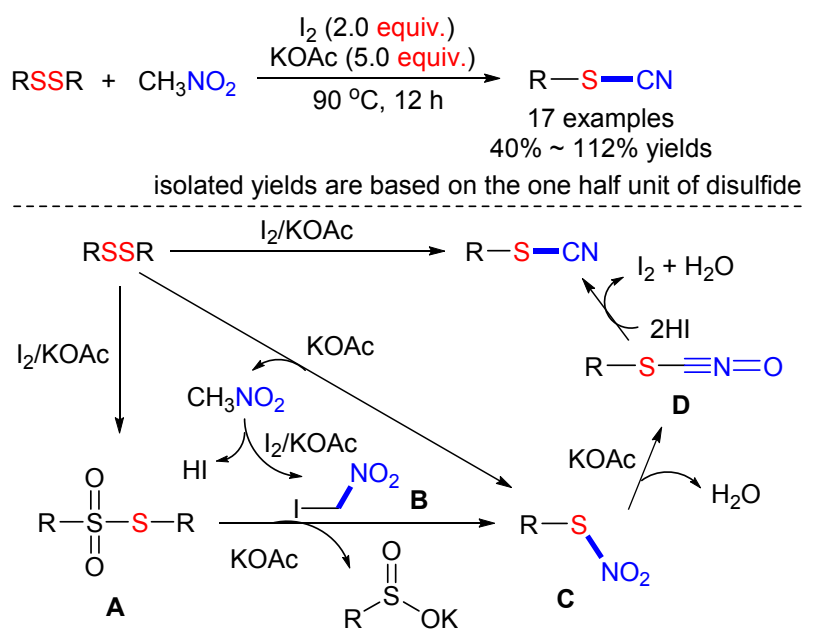

图式 21 以硝基甲烷为氰化试剂合成硫氰酸酯

Scheme 21 Nitromethane as a cyanating reagent for the synthesis of thiocyanates

\section{2 硫氰酸酯的应用}

硫氰酸酯类化合物广泛应用于有机合成领域. 作为 重要的有机合成中间体, 硫氰酸酯通过简单转化就可得 到硫醇、硫醚、二硫醚、含硫杂环、硫代磷/硫酸酯、异 硫氰酸酯等多种有机硫化物, 同时它还可作为氰化试剂 很好地参与反应.

\section{1 合成硫醇}

2009 年 Peters 课题组 ${ }^{[53]}$ 在合成硫代酯类抗癌醚脂 质 $(S$-ProAEL)的方案中, 有涉及将硫氰化物还原成硫醇 的步骤(Eq. 20). 在乙醚中, 加入 $\mathrm{LiAlH}_{4}$ 还原硫氰化物, 能以 $96 \%$ 的收率得到硫醇.

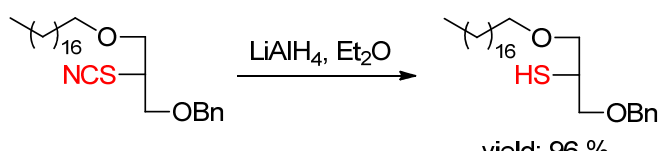

yield: $96 \%$

2015 年 Brown 等 ${ }^{[54]}$ 报道了一种有趣的方法来修复 肽或蛋白质的三维构象(Scheme 22)，具体是将硫醇与 1,2-二氯四嗪结合, 这使得两个半胱氨酸结合在一起, 形成一种桥形结构. 随后经紫外光照射, 这种结构被选 择性地破坏，得到相应的二硫氰酸酯肽，其在游离的半 胱氨酸作用下可以生成硫醇. 值得注意的是, 在经过这 一系列转变后肽的结构未发生改变.

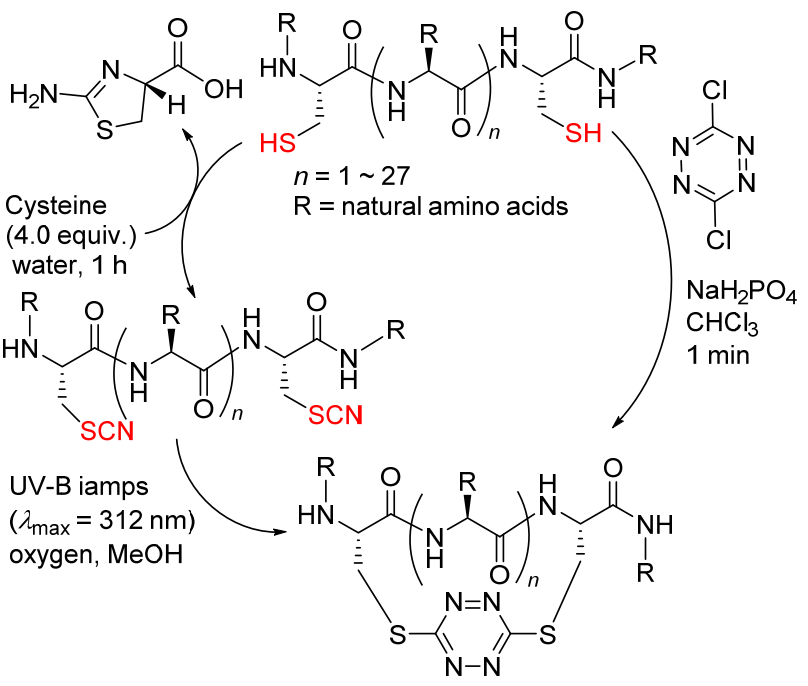

图式 22 肽/蛋白质的固定和展开

Scheme 22 Stapling and unstapling of peptides/proteins

\section{2 合成硫醚}

2011 年, Zhou 课题组 ${ }^{[55]}$ 开发了使用硫氰化钾和卤 代烷烃合成硫醚的反应(Eq. 21). 以水为溶剂, 碳酸铯为 碱，1,10-菲咯啉作配体，铜为催化剂和四丁基氟化铵作 相转移催化剂, 历经 $48 \mathrm{~h}$ 后得到产物. 此外, 当加入两 种不同卤代芳烃能以优异的收率合成不对称硫醚. 他们 认为首先卤代芳烃和硫氰化钾反应产生关键中间体苯 基硫氰酸酯，再经铜催化与卤代芳烃发生交叉偶联反应 得到硫醚产物。

Hajipour 小组 ${ }^{[56]}$ 于 2014 年研发了一种新型钯催化 剂 $[\mathrm{DBNT}]\left[\mathrm{PdCl}_{4}\right]$ ，在 DMSO 溶剂中，以甾代芳烃和硫 氰化钾为原料，氢氧化钾作碱，以良好到优异的收率得 到硫醚产物(Eq. 22). 反应机理与 Zhou 课题组 ${ }^{[55]}$ 类似. 

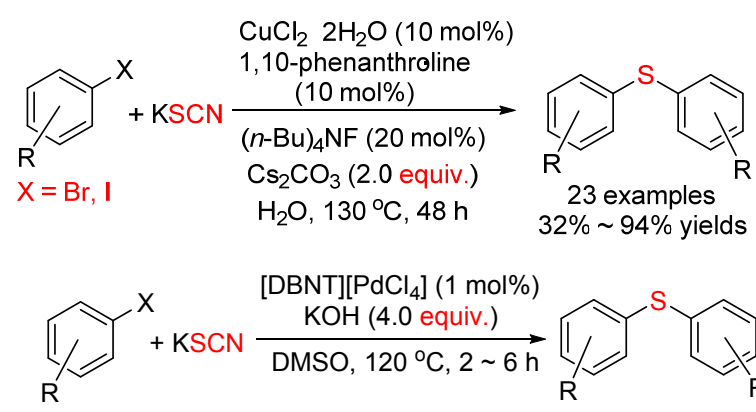

[DBNT][PdCl 4 ] (1 mol\%) $\mathrm{X}=\mathrm{Cl} . \mathrm{Br}, \mathrm{I}$ DMSO, $120^{\circ} \mathrm{C}, 2 \sim 6 \mathrm{~h}$
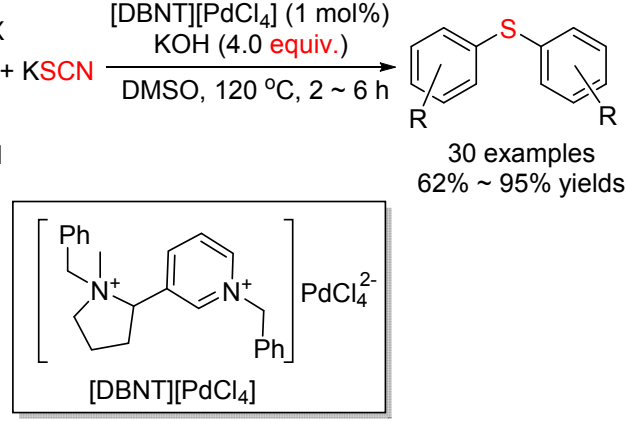

30 examples $62 \% \sim 95 \%$ yields

2015 年 Werz 小组 ${ }^{\left[{ }^{[7]}\right.}$ 开发了一条硫氰酸酯同时作为 氧化试剂和硫化试剂的高原子经济利用率的新路径(Eq. 23). 以乙腈为溶剂, 氟化铯作碱, Xantphos 为配体, 钯 为催化剂和氧气作氧化剂, 一步构建 C-SAr 和 C- $\mathrm{CN}$ 键，以 $42 \% \sim 81 \%$ 的收率得到产物.

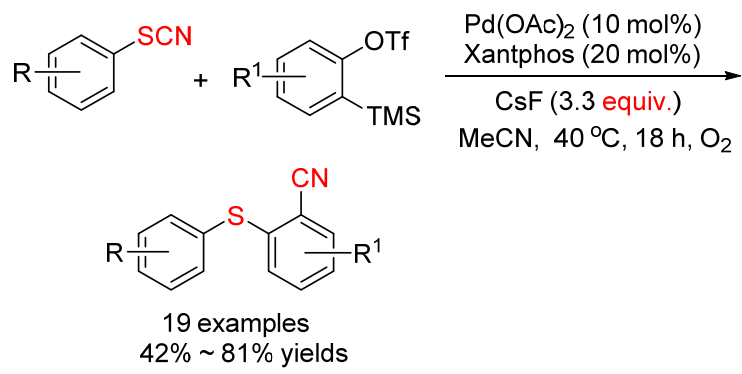

\section{3 合成二硫醚}

Wang 课题组 ${ }^{[58]}$ 于 2014 年发现硫䐂、烷基卤化物和 硫氧酸酯在一定条件下, 可合成茮基烷基二硫化物(Eq. 24). 在水中, 以磷酸钾作碱, 加入碘化钾和四丁基卤化 铵(TBAH)后, 经微波处理 $15 \mathrm{~min}$ 以最高 $90 \%$ 的收率得 到产物.

$$
\text { i }
$$

\section{4 合成含硫杂环}

2009 年, Gotor 等 ${ }^{[59]}$ 发现在甲醇溶液中加入嗍氢化 钠, 不仅实现羰基部分还原, 而且形成新五元杂环, 得 到 2-亚氨基-1,3-氧硫杂环戊烷及其衍生物(Eq. 25). 他 们认为存在氢化物和甲醇盐时, 羊基硫氰酸盐中间体的 $\mathrm{OH}$ 基能去质子化，而这过程恰恰是环化步骤基础.

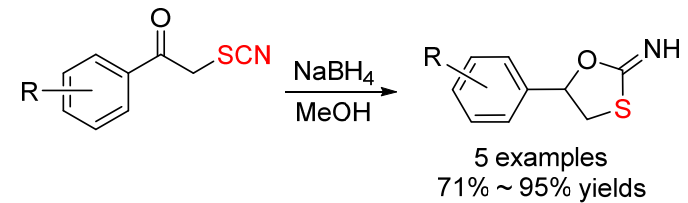

苯并异噻唑-3(2H)-酮衍生物可用于制药领域, 因其 具有抑制真菌和细菌的作用, 通常采用 2,2'二二硫代水杨 酸与胺反应 ${ }^{[60]}$. 由于其在药物市场中的强烈需求, 开发 出原料易得且收率较优的方法显得十分必要. 2012 年, $\mathrm{Xi}$ 课题组 ${ }^{[61]}$ 以水为溶剂, 1,4-二氮杂双环 [2.2.2]辛烷 (DABCO)作碱，邻菲罗啉作配体和铜为催化剂的条件 下, 实现邻溴苯甲酰胺衍生物与硫氰酸钾反应(Eq. 26). 通过一锅两步法, 先形成 $\mathrm{S}-\mathrm{C}$ 键, 再环化构建 $\mathrm{S}-\mathrm{N}$ 键, 此法可用于合成苯并异噻唑-3(2H)-酮衍生物.

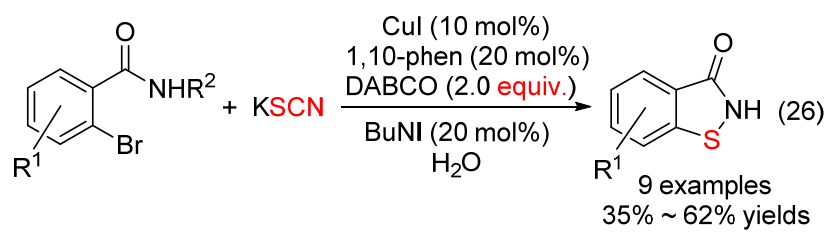

四氮唑能用于制药、高能材料等领域，关于合成它 的方法大部分基于 Finnegan 等的工作 ${ }^{[62]}$, 腈在叠氮化钠 和氯化铵存在下形成四氮唑. 虽然在此基础上已有化学 家提出改进方案 ${ }^{[63 ~ 65]}$, 但这些方法条件较为苛刻且反 应时间较长. 2014 年, Myznikov 小组 ${ }^{[66]}$ 开发了一条将硫 氰酸酯转化为四唑衍生物的新路径(Eq. 27). 在异丙醇 溶剂中, 加入氯化锌和叠氮化钠, 搅拌 $1.5 \mathrm{~h}$ 即可得到四 氮唑产物. 该方法条件温和，反应时间短，底物适用性 广，为四氮唑类化合物的合成提供新策略.

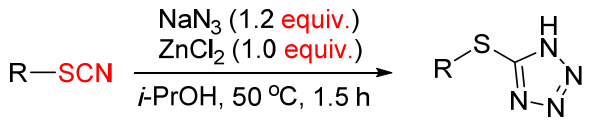

$$
\begin{aligned}
& 6 \text { examples } \\
& 47 \% \sim 92 \% \text { yields }
\end{aligned}
$$

\section{5 合成硫代磷/硫酸酯}

硫代磷酸酯越来越广泛地用于生物领域, 主要包括 害虫防治酶稳定的磷酸类似物，以及用于化学疗法的不 可水解核糖核苷酸模拟物 ${ }^{[67,68]}$. 2002 年, Mioskowski 等 ${ }^{[69]}$ 在硫代磷酸酯的合成中获得新途径(Eq. 28). 他们 以二取代膦氧化物和硫氰酸酯为原料, 在温和无水条件 下, 经碱催化能以中等到优异的收率得到硫代磷酸酯.

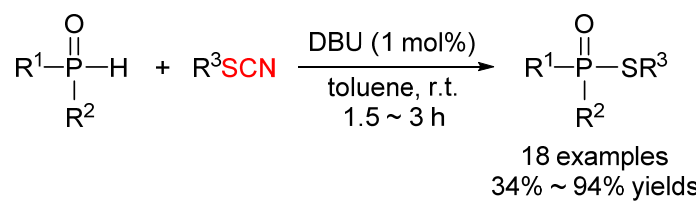


2013 年, Janeba 课题组 ${ }^{[70]}$ 报道了在室温下的 $N, N-$ 二 甲基甲酰胺(DMF)溶剂中, 实现(杂)芳族硫氰酸酯制备 硫代硫酸酯反应(Eq. 29). 经亚硫酸钠处理两小时后以 最高 $74 \%$ 收率得到重要的化工中间体 Bunte 盐.

$$
\begin{aligned}
& \operatorname{RSCN} \frac{\mathrm{Na}_{2} \mathrm{SO}_{3} \text { (2.0 equiv.) }}{\mathrm{H}_{2} \mathrm{O} \& \operatorname{DMF}(3: 1) \text {, r.t., } 2 \mathrm{~h}} \mathrm{RS}-\stackrel{\prod_{\mathrm{O}}^{\mathrm{O}}}{\mathrm{O}}-\mathrm{O}^{-} \mathrm{Na}^{+} \\
& 15 \text { examples } \\
& 15 \% \sim 74 \% \text { yields }
\end{aligned}
$$

\section{6 合成异硫氰酸酯}

Gonda 等 ${ }^{[71]}$ 发现某些硫氰酸盐可通过 $[3,3]-\sigma$-重排 选择性地得到 3-(S)-异硫氰酸根合-3-脱氧-3-C-乙烯基葡 萄糖(Scheme 23). 值得一提的是, 即使底物中存在不同 的立体异构体, 经过重排后均得到同一种产物. 此外作 者通过密度泛函理论(DFT)计算认为, 产物的立体选择 性是硫氰根与 1,2- $O$-异亚丙基在空间上相互作用的结 果.

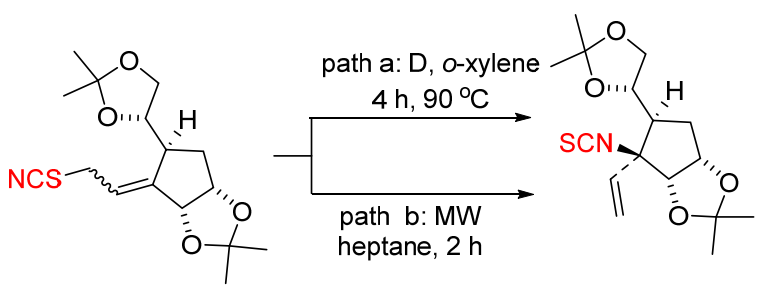

图式 23 硫氰酸烯丙酯[3,3]- $\sigma$-重排合成 $\alpha$-异硫氰酸酯

Scheme 23 Synthesis of $\alpha$-quaternary isothiocyanate by [3,3]$\sigma$-rearrangement of allyl thiocyanate

\section{7 其他转化}

腈类化合物存在于天然产品, 是药品中关键部分, 能作为染料和除草剂等 ${ }^{[72]}$. 过渡金属催化卤代芳烃与 氭化物反应广泛用于制备芳基腈化合物. 但通常氭化反 应使用剧毒的无机氰化物, 不利于绿色生产发展. 2006 年, Liebeskind 等 ${ }^{[73]}$ 发现在噻吩-2-羧酸铜(I) (CuTC) 和钯 共同催化作用下, 硫氰酸茮酯可作为很好的㲵化试剂与 芳基硼酸进行交叉偶联反应(Eq. 30).

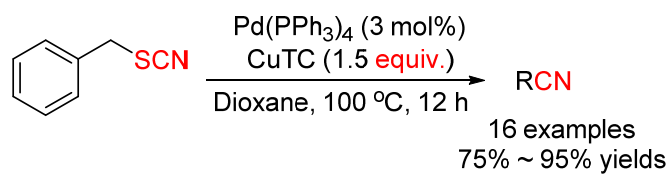

Chung 课题组 ${ }^{[74}$ 于 2007 年以对甲苯基硫氧酸酯为 氭化试剂, 与炔烃氰化反应(Eq. 31). 以苯为溶剂和钯作 催化剂, 经微波处理, 仅需 $1 \mathrm{~h}$ 即能以 $62 \%$ ～ $83 \%$ 收率得 到双官能团化烯烃产物.

2014 年, Rozen 等 ${ }^{[75]}$ 利用硫氰酸酯为原料, 开发了 一种合成三氟甲基硫化物的新方法(Scheme 24). 以三 氟甲烷为起始原料, 在强碱叔丁醇钾作用下与氯化亚铜

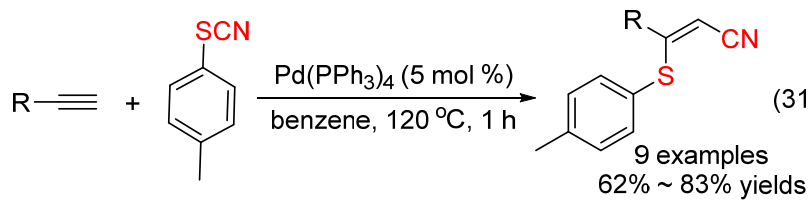

反应得到三氟甲基铜，接着其与硫氰酸酯反应得到产 物. 该方法为大气污染物氟利昂类化合物的有利转化提 供了很好的借鉴思路.

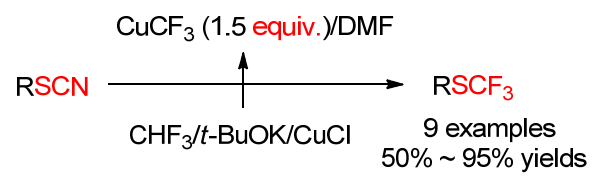

图式 24 铜催化硫氰根转化为三氟甲基化硫化物 Scheme 24 Copper-mediated transformation of thiocyanate into trifluoromethylated sulfides

2015 年, Goossen 小组 ${ }^{[76]}$ 发现由 $N$-硫氰酰琥珀酰亚 胺(NTS)与芳烃得到的硫氰酸酯, 可进一步转化得到三 氟甲基硫醚或二氟甲基硫醚(Scheme 25). 首先富电子 芳烃在 $\mathrm{AlCl}_{3}$ 催化下实现硫氰化反应，中间产物硫氰酸 酯在碳酸铯作用下与 $\mathrm{TMSCF}_{3}$ 反应得到三氟甲基硫醚; 此外硫氰酸酯在铜催化下与 $\mathrm{TMSCF}_{2} \mathrm{H}$ 反应生成二氟甲 基硫醚. 他们发现这两个过程均在富电子且空阻最小位 置上进行.

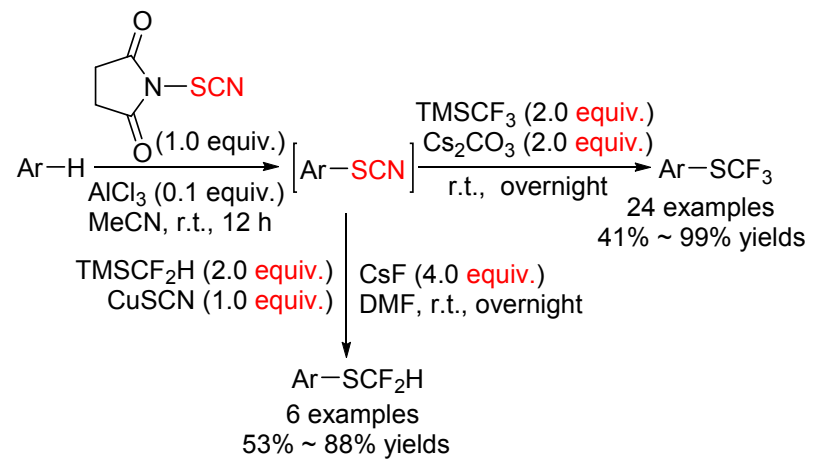

图式 25 合成芳基二/三氟甲基硫醚

Scheme 25 Synthesis of aryl di- and trifluoromethyl thioethers

\section{3 总结与展望}

近几年来, 各种各样的硫氰酸酯类化合物合成新方 法、新策略层出不穷. 直接硫氰化反应是合成硫氰酸酯 类化合物的重要方法. 此外, 各种有机硫化物的氰化反 应大大拓宽了硫氰酸酯类化合物的合成途径. 随着硫氰 酸酯合成方法研究的不断推进，这类化合物的应用研究 也发展迅速. 然而, 在应用的过程中也面临着底物原子 利用率低、经济性差等问题. 以硫氰酸酯作为双官能团 合成子不仅可以提高原子利用率，而且可以丰富氮硫化 合物的分子库，为这类化合物的应用与研究指明了新方 
向.

\section{References}

[1] Elhalem, E.; Bailey, B. N.; Docampo, R.; Ujvary, I.; Szajnman, S. H.; Rodriguez, J. B. J. Med. Chem. 2002, 45, 3984.

[2] Kokorekin, V. A.; Terent'ev, A. O.; Ramenskaya, G. V.; Grammatikova, N. E.; Rodionava, G. M.; llovaiskii, A. I. Pharm. Chem. J. 2013, 47, 422.

[3] Dutta, S.; Abe, H.; Aoyagi, S.; Kibayashi, C.; Gates, K. S. J. Am. Chem. Soc. 2005, 127, 15004.

[4] Capon, R. J.; Skene, C.; Liu, E. H.-T.; Lacey, E.; Gill, J. H.; Heiland, K.; Friedel, T. J. Org. Chem. 2001, 66, 7765.

[5] Yasmana, Y.; Edrada, R. A.; Wray, V.; Proksch, P. J. Nat. Prod. 2003, 66, 1512 .

[6] Billard, T.; Large, S.; Langlois, B. R. Tetrahedron Lett. 1997, 38, 65.

[7] Johnson, T. B.; Douglass, I. B. J. Am. Chem. Soc. 1939, 61, 2548.

[8] Sabacky, M. J.; Johnson, S. M.; Martin, J. C.; Paul, I. C. J. Am. Chem. Soc. 1969, $91,7542$.

[9] Aureggi, V.; Sedelmeier, G. Angew. Chem. Int. Ed. 2007, 46, 8440.

[10] Ciszek, J. W.; Stewart, M. P.; Tour, J. M. J. Am. Chem. Soc. 2004, 126,13172

[11] Still, I. W. J.; Toste, F. D. J. Org. Chem. 1996, 61, 7677.

[12] Castanheiro, T.; Suffert, J.; Donnard, M.; Gulea, M. Chem. Soc. Rev. 2016, 45, 494.

[13] Sun, N.; Che, L.-S.; Mo, W.-M.; Hu, B.-X.; Shen, Z.-L.; Hu, X.-Q. Org. Biomol. Chem. 2015, 13, 691.

[14] Zhu, N.; Wang, F.; Chen, P.-H.; Ye, J.-X.; Liu, G.-S. Org. Lett. 2015, 17, 3580 .

[15] Jiang, H.-F.; Yu, W.-T.; Tang, X.-D.; Li, J.-X.; Wu, W.-Q. J. Org Chem. 2017, 82, 9312.

[16] Chen, Y.-T.; Wang, S.-F.; Jiang, Q.-W.; Cheng, C.-G.; Xiao, X.-H.; Zhu, G.-G. J. Org. Chem. 2018, 83, 716

[17] Rad, M. N. S. J. Chem. Res. 2016, 40, 583.

[18] Dwivedi, V.; Rajesh, M.; Kumar, R.; Kantc, R.; Reddy, M. S. Chem. Commun. 2017, 53, 11060 .

[19] Palsuledesai, C. C.; Murru, S.; Sahoo, S. K.; Patel, B. K. Org. Lett. 2009, 11, 3382.

[20] Modi, A.; Ali, W.; Patel, B. K. Org. Lett. 2017, 19, 432.

[21] Yadav, A. K.; Yadav, L. D. S. Tetrahedron Lett. 2015, 56, 6696.

[22] Zhang, D.; Wang, H.; Bolm, C. Chem. Commun. 2018, 54, 5772.

[23] Liang, S.; Zeng, C.-C.; Tian, H.-Y.; Sun, B.-G.; Luo, X.-G.; Ren, F.-Z. Adv. Synth. Catal. 2018, 360, 1444

[24] Xiong, H.-Y.; Pannecoucke, X.; Besset, T. Org. Chem. Front. 2016, 3,620 .

[25] Zhang, H.-L.; Wei, Q.; Wei, S.-Q.; Qu, J.-P.; Wang, B.-M. Eur. J. Org. Chem. 2016, 20, 3373.

[26] Chen, Q.; Lei, Y.-J.; Wang, Y.-F.; Wang, C.; Wang, Y.-N.; Xu, Z.-Q.; Wang, H.; Wang, R. Org. Chem. Front. 2017, 4, 369.

[27] Wang, Z.-H.; Wang, L.; Chen, Q.; He, M.-Y. Synth. Commun. 2018, $40,76$.

[28] Venkanna, P.; Rajanna, K. C.; Kumar, M. S.; Venkateswarlu, M.; Ali, M. M. Synlett 2016, 27, 237

[29] Qiu, J.-S.; Wu, D.; Karmaker, P. G.; Yin, H.-Q.; Chen, F.-X. Org. Lett. 2018, 20, 1600.

[30] Wu, D.; Qiu, J.-S.; Karmaker, P. G.; Yin, H.-Q.; Chen, F.-X. J. Org. Chem. 2018, 83, 1576

[31] Yang, H.; Duan, X.-H.; Zhao, J.-F.; Guo, L.-N. Org. Lett. 2015, 17, 1998.

[32] Yang, D.-S.; Yan, K.-L.; Wei, W.; Li, G.-Q.; Lu, S.-L.; Zhao, C.-X.; Tian, L.-J.; Wang, H. J. Org. Chem. 2015, 80, 11073

[33] Zhang, X.-Z.; Ge, D.-L.; Chen, S.-Y.; Yu, X.-Q. RSC Adv. 2016, 6, 66320.

[34] Guo, L.-N.; Gu, Y.-R.; Yang, H.; Hu, J. Org. Biomol. Chem. 2016, 14, 3098.

[35] Chen, J.-C.; Wang, T.-Y.; Wang, T.; Lin, A.-J.; Yao, H.-Q.; Xu, J.-Y. Org. Chem. Front. 2017, 4, 130.
[36] Mete, T. B.; Khopade, T. M.; Bhat, R. G. Tetrahedron Lett. 2017, 58,415 .

[37] Ji, F.; Fan, Y.; Yang, R.; Yang, Y.-Y.; Yu, D.-W.; Wang, M.-Y.; Li, Z.-Y. Asian J. Org. Chem. 2017, 6, 682 .

[38] Karmaker, P. G.; Qiu, J.; Wu, D.; Yin, H.; Chen, F. X. Synlett 2018 , 29, 954

[39] Zeng, Y.-F.; Tan, D.-H.; Chen, Y.-Y.; Lv, W.-X.; Liu, X.-G.; Li, Q.-J.; Wang, H.-G. Org. Chem. Front. 2015, 2, 1511.

[40] Lv, Y.-H.; Pu, W.-Y.; Cui, H.; He, J.-L.; Zhang, Q.-M. Synth. Commun. 2016, 46, 1223 .

[41] Tao, Z.-K.; Li, C.-K.; Zhang, P.-Z.; Shoberu, A.; Zou, J.-P.; Zhang, W. J. Org. Chem. 2018, 83, 2418.

[42] Fan, W.-G.; Yang, Q.; Xu, F.-S.; Li, P.-X. J. Org. Chem. 2014, 79, 10588.

[43] Mitra, S.; Ghosh, M.; Mishra, S.; Hajra, A. J. Org. Chem. 2015, 80 , 8275.

[44] Wang, L.; Wang, C.-C.; Liu, W.-J.; Chen, Q.; He, M.-Y. Tetrahedron Lett. 2016, 57, 1771.

[45] Singh, M.; Yadav, A. K.; Yadav, L. D. S.; Singh, R. K. P. Synlett 2018, 29, 176

[46] Li, W.; Yang, C.; Gao, G.-L.; Xia, W.-J. Chin. J. Org. Chem. 2017, 37,480 (in Chinese). (李伟，杨超，高国林，夏吾昫，有机化学，2017, 37, 480.)

[47] Castanheiro, T.; Gulea, M.; Donnard, M.; Suffert, J. Eur. J. Org. Chem. 2014, 7814.

[48] Guo, W.; Tan, W.; Zhao, M.; Zheng, L.; Tao, K.; Chen, D.; Fan, X. J. Org. Chem. 2018, 83, 6580.

[49] Frei, R.; Courant, T.; Wodrich, M. D.; Waser, J. Chem.-Eur. J. 2014, $20,1$.

[50] Zhu, D.; Chang, D.-H.; Shi, L. Chem. Commun. 2015, 51, 7180.

[51] Teng, F.; Yu, J.-T.; Yang, H.-T.; Jiang, Y.; Cheng, J. Chem. Commun. 2014, 50, 12139

[52] Wang, Z.-H.; Ji, X.-M.; Hu, M.-L.; Tang, R.-Y. Tetrahedron Lett. $\mathbf{2 0 1 5}, 56,5067$.

[53] Linderoth, L.; Fristrup, P.; Hansen, M.; Melander, F.; Madsen, R.; Andresen, T. L.; Peters, G. H. J. Am. Chem. Soc. 2009, 131, 12193.

[54] Brown, S. P.; Smith, A. B. III J. Am. Chem. Soc. 2015, 137, 4034.

[55] Ke, F.; Qu, Y.-Y.; Jiang, Z.-Q.; Li, Z.-K.; Wu, D.; Zhou, X.-G. Org. Lett. 2011, 13, 454.

[56] Hajipour, A. R.; Pourkaveh, R.; Karimi, H. Appl. Organomet. Chem. 2014, 28, 879 .

[57] Pawliczek, M.; Garve, L. K. B.; Werz, D. B. Org. Lett. 2015, 17, 1716.

[58] Lu, X.-G.; Wang, H.-M.; Gao, R.-L.; Sun, D.-M.; Bi, X.-J. RSC Adv. 2014, 4, 28794

[59] Bisogno, F. R.; Cuetos, A.; Lavandera, I.; Gotor, V. Green Chem. 2009, 11,452 .

[60] Sano, T.; Takagi, T.; Gama, Y.; Shibuya, I.; Shimizu, M. Synthesis 2004, 1585 .

[61] Wang, F.; Chen, C.; Deng, G.; Xi, C.-J. J. Org. Chem. 2012, 77, 4148.

[62] Finnegan, W. G.; Henry, R. A.; Lofquist, R. J. Am. Chem. Soc. 1958, 80, 3908 .

[63] Roh, J.; Artamonova, T. V.; Vavrova, K.; Koldobskii, G. I.; Hrabalek, A. Synthesis 2009, 2175.

[64] Roh, J.; Vavrova, K.; Hrabalek, A. Eur. J. Org. Chem. 2012, 31, 6101.

[65] Yoneyama, H.; Usami, Y.; Komeda, S.; Harusawa, S. Synthesis 2013, 45, 1051.

[66] Vorona, S.; Artamonova, T.; Zevatskii, Y.; Myznikov, L. Synthesis 2014, 46, 781

[67] Marshall, W. S.; Caruthers, M. H. Science 1993, 259, 1564.

[68] Cieslak, J.; Jankowska, J.; Stawinski, J.; Kraszewski, A. J. Org. Chem. 2000, 65, 7049.

[69] Renard, P.-Y.; Schwebel, H.; Vayron, P.; Josien, L.; Valleix, A.; Mioskowski, C. Chem.-Eur. J. 2002, 8, 2910.

[70] Jansa, P.; Cechova, L.; Dracínsky, M.; Janeba, Z. RSC Adv. 2013, 3, 2650. 
[71] Gonda, J.; Martinková, M.; Raschmanová, J.; Balentová, E. Tetrahedron: Asymmetry 2006, 17, 1875.

[72] Sundermeier, M.; Zapf, A.; Beller, M.; Sans, S. Tetrahedron Lett. 2001, 42, 6707.

[73] Zhang, Z.-H.; Liebeskind, L. S. Org. Lett. 2006, 8, 4331.
[74] Lee, Y. T.; Choi, S. Y.; Chung, Y. K. Tetrahedron Lett. 2007, 48, 5673.

[75] Potash, S.; Rozen, S. J. Fluorine Chem. 2014, 168, 173.

[76] Jouvin, K.; Matheis, C.; Goossen, L. J. Chem.-Eur. J. 2015, 21, 14324

(Li, L.; Fan, Y.) 